Post-print of: Alonso-Carrera, Jaime; Caballé, Jordi; Raurich, Xavier "Fiscal policy, composition of intergenerational transfers, and income distribution" in Journal of economic behavior \& organization, Vol. 84 (2012) , p. 62-84, ISSN 0167-2681.

The final version is available at DOI: 10.1016/j.jebo.2012.07.013

\title{
Fiscal policy, composition of intergenerational transfers, and income distribution*
}

\author{
Jaime Alonso-Carrera ${ }^{\dagger}$ \\ Universidade de Vigo \\ Jordi Caballé \\ Universitat Autònoma de Barcelona and Barcelona GSE \\ Xavier Raurich ${ }^{\S}$ \\ Universitat de Barcelona
}

July 10, 2012

\begin{abstract}
In this paper, we characterize the relationship between the initial distribution of human capital and physical inheritances among individuals and the long-run distribution of these two variables. In a model with indivisible investment in education, we analyze how the initial distribution of income determines the posterior intergenerational mobility in human capital and the evolution of intragenerational income inequality. This analysis enables us in turn to characterize the effects of fiscal policy on future income distribution and mobility when the composition of intergenerational transfers is endogenous. To this end, we consider the following government interventions: a pay-as-you-go social security system, a tax on inheritance, a tax on capital income, a tax on labor income, and a subsidy on education investment.
\end{abstract}

JEL classification codes: D64, E21, E13, E62

Keywords: Altruism, Intergenerational Transfers, Human Capital, Income Distribution.

* We are grateful to participants in the European Economic Association Congress (Milan), Association of Southern European Economic Theorists Meeting (Florence), the Simposio de Analisis Economico (Granada), and the Paris School of Economics Macroeconomics Seminar for their useful comments. Financial support from the Fundación Ramón Areces; MOVE; FEDER; the Spanish Ministry of Education through grants ECO2008-02752, ECO2009-09847, ECO2009-06953, and ECO2011-23959; the Generalitat of Catalonia through the grants SGR2009-00350 and SGR2009-1051; and Xunta de Galicia through grant 10PXIB300177PR is also gratefully acknowledged.

\footnotetext{
${ }^{\dagger}$ Postal address: Departamento de Fundamentos del Análisis Económico and RGEA. Universidade de Vigo. Facultad de Ciencias Económicas y Empresariales. Universidade de Vigo. Campus As LagoasMarcosende. 36310 Vigo (Pontevedra), Spain. E-mail address: jalonso@uvigo.es

${ }^{\ddagger}$ Corresponding author: Jordi Caballé. Postal address: Departament d’Economia i d’Història Econòmica. Universitat Autònoma de Barcelona. Edifici B. 08193 Bellaterra (Barcelona), Spain. E-mail address: jordi.caballe@uab.eu. Phone: (+34)935.812.367. Fax: $(+34) 935.812 .012$

$\S$ Postal address: Departament de Teoria Econòmica and CREB. Universitat de Barcelona. Facultat d'Economia i Empresa. Avinguda Diagonal, 690. 08034 Barcelona, Spain. Phone: (+34)934.024.333. E-mail address: xavier.raurich@ub.edu
} 


\section{Introduction}

The question of how inequality is generated and evolves over time is one of the major concerns in economic analysis. In the last decades a large number of studies have provided evidence supporting the presumption that intergenerational transfers are key to explain the empirical distribution of income and wealth. ${ }^{1}$ Moreover, as intergenerational transfers could take the form of either physical capital (through bequests) or human capital (through investment in education), there is also empirical evidence documenting that both types of transfers affect the distribution of relevant economic variables among individuals. For instance, the empirical analysis of d'Addio (2007) confirms both the importance of education on mobility and the intergenerational persistence of inequality. In this paper, we follow this line of research and show analytically how the joint initial distribution of bequest and human capital, as well as fiscal policy, determines the average level and the intragenerational distribution of income in the long run.

Investment in education is a key factor of income inequality. ${ }^{2}$ As was pointed out by Galor and Zeira (1993), and many other papers, there are two main features that give rise to this relationship. On the one hand, the technology of human capital accumulation exhibits a non-convexity since the investment in education is indivisible. This technological feature implies that access to education by the poorest individuals depends on whether they can borrow or not. On the other hand, when there are capital market imperfections resulting in borrowing constraints, those individuals with an income below some threshold value cannot afford the cost of education. ${ }^{3}$ Therefore, the initial distribution of wealth determines the number of individuals who can acquire education and, thus, the aggregate stock of human capital and the rate of economic growth. This mechanism linking education with income distribution and growth was already widely analyzed in the literature by authors like Galor and Zeira (1993), GarcíaPeñalosa (1995), Galor and Tsiddon (1997), and Owen and Weil (1998), among others.

Intergenerational transfers from parents to children account for a part of the observed inequality since these transfers help to ameliorate the negative effects of borrowing constraints on the accumulation of human capital. In an environment with credit market imperfections, only those individuals who receive a sufficiently large inheritance can invest in human capital (see Becker and Tomes, 1976; Eckstein and Zilcha, 1994; or Behrman et al., 1995). Regarding the dynamics of income distribution, Galor and Zeira (1993) show that, if one assumes credit market imperfections and a non-convex education technology, then the inherited distribution of wealth entirely determines the accumulation of human capital and the dynamics of the distribution of income.

The literature that we have reviewed above has not considered simultaneously the two types of intergenerational transfers we have mentioned: (i) transfers of physical capital by means of bequests; and (ii) transfers of human capital by means of the parents' investment in the education of their children. In this paper, we consider the interaction between the composition of intergenerational transfers and income

\footnotetext{
${ }^{1}$ See, for instance, Becker and Tomes (1986), d'Addio (2007), Gokhale et al. (2001), Gokhale and Kotlikoff (2002), Laitner (2002) or Wolf (2002), among many others.

${ }^{2}$ García-Peñalosa (1994) or Aghion et al. (1999) review the literature that examines the role of education on the link between distribution and growth.

${ }^{3}$ See, for instance, Dynarski (2002) or Keane (2002) for a discussion of the role of borrowing constraints on decisions concerning human capital acquisition.
} 
distribution when education is financed by parents. ${ }^{4}$ To this end, our paper develops a model of a small open economy populated by overlapping generations of individuals who differ in the amount and composition of inherited transfers from parents. In this economy the disposable lifetime income of an individual is fully determined by the bequest and human capital inherited from his parent. In addition to the imperfection of the capital market and the non-convexity of the education technology, we introduce two crucial assumptions. One is that the intergenerational transfers arise because individuals care about the starting opportunities of their children and thus they take into account the disposable income of their offspring. More precisely, we assume that parents derive utility from their contribution to the future lifetime income of their children without discriminating between the two types of intergenerational transfers used for making such a contribution. The second important assumption is that there exists an asymmetry between the two types of intergenerational transfers as they take place at different moments of individual's lifetime and they exhibit different contributions to the offspring's lifetime income. Individuals can only attend to the school before going to the labor market and receiving a physical inheritance from their parents. Moreover, due to the borrowing constraints, individuals can only have access to education if their parents pay its cost. Finally, as it is standard in the literature, we assume the marginal return on human capital investment is larger than the marginal return on physical capital investment. Given our motive for intergenerational transfers, parents obtain thus larger marginal gains from investing in their children's education than from leaving bequest.

The income of parents then drives the total contribution to the future lifetime income of their children. The composition of this contribution between the two types of transfers is endogenous in our model and depends on the relative returns of these transfers. However, since we assume that the investment in education is indivisible and that parents cannot force their children to give them transfers, if the cost of education is sufficiently large, parents will not finance the cost of education and, thus, they will only leave bequest to their offspring. Obviously, this occurs to parents with an income level below some threshold. In this way, the initial distribution of income drives the evolution of the composition of intergenerational transfers and, thus, the size of the educated population along the equilibrium path. This simple mechanism explains how the initial distribution of income determines the posterior evolution of intragenerational income inequality and of intergenerational mobility in terms of human capital. This dynamics implies that, under reasonable parameter values, non-educated but sufficiently rich parents will educate their descendents and educated parents will always educate their descendents. Therefore, only upward mobility is possible in our simple model, which explains the increasing access to education in most countries during the second half of the last century. Our model also implies that social mobility ends when the economy reaches the steady state, which is characterized by a two-class society composed of rich educated individuals and poor non-educated individuals.

Our mechanism behind the dynamics of income distribution delivers two important insights for human capital accumulation, inequality, and growth. First, since the income of parents depends on the composition of their initial inheritance, the dynamics of economic activity depends not only on the initial distribution of wealth, but also on the

\footnotetext{
${ }^{4}$ In a related paper, Zilcha (2003) shows that differences in the composition of intergenerational transfers may partly explain the cross-country differences in growth and inequality. However, he assumes that this composition is exogenously given.
} 
initial distribution of human capital. Our model then characterizes a new mechanism relating the distribution of human capital with growth and inequality. Second, and probably more important, the relative return of human capital accumulation determines the access to education of the middle class. This result is quite intuitive. Since there is a wedge between the returns from the two types of transfers, there exists a non degenerated interval of income levels for which all the parents with those levels of income optimally choose to pay the education costs and to leave no physical bequest. Outside this interval, those parents with a larger income level educate and leave bequest, whereas those parents with a smaller income level leave bequest and do not educate. Therefore, both the accumulation of human capital and the dynamics of income inequality crucially depend on the initial mass of individuals with a level of income inside the aforementioned interval. Furthermore, the length of this interval is fully determined by the wedge between the contributions of each transfer to the lifetime income of children. Thus, for a given distribution of income, any shock altering the relative marginal return of education will change the fraction of individuals who will have access to education and, therefore, it will affect inequality, mobility, and growth. This is a feature that distinguishes our contribution from the one of Galor and Zeira (1993) since in their model the access to education only depends on the fixed cost of education, whereas in our model investment in education also depends on preference and fiscal policy parameters. ${ }^{5}$ Therefore, in our paper, fiscal policy will affect the education decision in a non-trivial way, which makes our framework particularly suitable to conduct the analysis of the effects of fiscal policy.

Our model is closely related to those in Galor and Moav (2004 and 2006), who also consider the two types of intergenerational transfers. However, they assume a joy of giving motive for intergenerational transfers, where parents' marginal utility from physical bequest and from human capital transfers are identical. Therefore, in those papers the composition of intergenerational transfers relies on an ad-hoc assumption, so that it does not depend on the relative return of investing in education. Moreover, these papers assume a convex technology of education, which implies that the composition of intergenerational transfers does not affect the mobility in earnings. In contrast, we provide a framework where fiscal policy affects mobility through the induced change in the composition of intergenerational transfers of the middle class.

In our setup all individuals are assumed to have the same learning ability so that the only difference among individuals arises from the predetermined initial income and education level of their parents. This assumption allows us to focus on the role of the composition of intergenerational transfers for the distribution of income in the long run. Allowing for random individually idiosyncratic abilities will deliver a stochastic version of the deterministic model considered in this paper. In this case the resulting dynamics and intergenerational mobility would be richer. However, we assume identical, non-stochastic abilities to make more transparent the mechanism driving the relation between the composition of intergenerational transfers and the subsequent dynamics of the economy.

A natural question to ask in our model is how different fiscal policies affect the

\footnotetext{
${ }^{5}$ In Galor and Zeira (1993) the access to education also depends on the skill premium when children are allowed to borrow. This is so because the more profitable is the investment in education, the larger is the number of individuals who will be able to pay back what they have borrowed. However, if the credit market is shut down for children, as it is assumed in our paper, only the cost of education determines the decision about the investment in education.
} 
evolution of both income distribution and mobility, where the latter determines in turn aggregate income in the long run. In this paper we analyze the effects of the following government instruments: a pay-as-you-go social security system, a tax on inheritances, a tax on capital income, a tax on labor income, and a subsidy on education investment. Note that our analysis is purely positive as we focus exclusively on the effects on human capital accumulation, inequality, and mobility of traditional macroeconomic tax instruments. This analysis is performed in Sections 5 and 6. In Section 5, we study the effects of modifying only one of the aforementioned government instruments and, among other results, we obtain that raising the tax rate on either inheritance or labor income results in a larger fraction of non-educated individuals in the total population, in a smaller individual amount of bequest, and in smaller inequality in initial wealth between educated and non-educated individuals. Therefore, these taxes have some equalizing effects but decrease the accumulation of human capital as individuals enjoy less disposable income to pay for the indivisible cost of education of their children. We characterize the effects of a pay-as-you-go social security system, which will depend on whether the economy is dynamically efficient or inefficient. When it is dynamically efficient, the introduction of a pension system implies a reduction in human capital accumulation and, hence, an income loss. We also analyze the quite neutral role on human capital accumulation played by the tax on capital income and the disequalizing effects triggered by education subsidies. These subsidies only benefit the educated families and hence they increase inequality.

Finally, in Section 6 we study the effects of financing either government spending or education subsidies through labor income taxes instead of through inheritance taxes. We show that this substitution increases human capital and aggregate income, whereas the effect on income inequality between educated and non-educated individuals depends on the initial frequency distribution of these two types of individuals.

The paper is organized as follows. Section 2 presents the model of overlapping generations with altruistic individuals. Section 3 solves the intertemporal choice problem faced by an individual. In section 4 we describe the dynamics of the joint distribution of bequest and human capital following a given initial distribution. In section 5 and 6 we analyze the effects of fiscal policy on the intergenerational mobility in human capital and on the stationary distribution of income. Section 7 concludes the paper.

\section{The model}

We consider a small open economy populated by overlapping generations of individuals who live for three periods. There is a continuum of dynasties distributed on the interval $[0,1]$. A new generation of individuals is born in each period within each dynasty. Each individual has offspring at the beginning of the second period of his life and the number of children per parent is $n \geq 1$. An agent makes economic decisions only during the last two periods of his life. In every period, the youngest individuals neither consume nor work, but they can accumulate human capital by attending formal school. We assume that individuals can accumulate human capital only during the first period of their lives. Individuals work and supply inelastically one unit of labor when they are adult (second period of life) and are retired when they are old (third period of life).

Individuals are assumed to care about their contribution to the future income of their children and they can give them two kinds of transfers: physical bequest and education. 
We will use the convention that the generation $t$ is composed of the individuals who are adult (workers) in period $t$.

Individuals derive utility from both their own lifetime consumption and their contribution to the lifetime income of their children. Preferences of an individual belonging to dynasty $i$ and generation $t$ are represented by the utility function:

$$
U_{t}^{i}=\ln c_{t}^{i}+\rho \ln x_{t+1}^{i}+\beta \ln I_{t+1}^{i},
$$

where $\rho>0$ is the temporal discount factor, the coefficient $\beta>0$ measures the intensity of altruism, $c_{t}^{i}$ and $x_{t+1}^{i}$ are the amounts of consumption in the second and third periods of life, respectively, and $I_{t+1}^{i}$ is the after-tax contribution to the future lifetime income of each of their children. The parental contribution to the income of an individual belonging to dynasty $i$ and generation $t+1$ is then given by

$$
I_{t+1}^{i}=\left(1-\tau_{w}\right) w_{t+1} \Delta_{t+1}^{i}+\left(1-\tau_{b}\right) b_{t+1}^{i},
$$

where $w_{t+1}$ is the wage per efficiency unit of labor at period $t+1, \tau_{w} \in[0,1)$ is the tax rate on labor income, $\Delta_{t+1}^{i}$ is the increase in the number of efficiency units of labor supplied by an individual belonging to dynasty $i$ and generation $t+1$ thanks to the investment in education made by his parent, $b_{t+1}^{i}$ is the amount of inheritance that an individual of dynasty $i$ and generation $t+1$ receives from his parent, and $\tau_{b} \in[0,1)$ is the tax rate on inheritances.

We assume that individuals do not discriminate among their children so that they make the same contribution $I_{t+1}^{i}$ for all their direct descendants. ${ }^{6}$ Therefore, this equal treatment assumption, together with the lack of individually idiosyncratic shocks on preferences, ability or productivity, implies that all the individuals belonging to the same dynasty $i \in[0,1]$ and to the same generation $t$ will be identical in all respects. However, on the one hand, individuals belonging to the same dynasty but different generation could differ due to the different transfers they receive. On the other hand, individuals belonging to the same generation but different dynasty will also differ in the amount of transfers they receive if the initial endowments of their respective dynasties are not identical.

The assumption that individuals derive utility from their contribution to the future lifetime income of their children with independency of whether this contribution takes the form of a direct transfer or of an education investment is consistent with the formulation of altruism defended in Becker and Tomes (1986). It seems reasonable in our economy to modify the pure "joy of giving" motive, where individuals receive direct utility from the act of giving, by not considering only the total expenditure in children as a source of felicity. We propose that, instead of the parents' expenditure, it is the income received by the direct descendents what matters for parental felicity. That received income arises indirectly from the after-tax increase in wages due to the higher individual productivity of educated workers and directly from the after-tax physical inheritance. Our notion of altruism lies thus between the "joy-of-giving" motive and "family altruism", where individuals' felicity depends on the disposable income of their children. ${ }^{7}$

Let $e_{t}^{i}$ denote the income that the adult individual of dynasty $i$ and generation $t$ devotes to finance the education of each of their children. We assume that the level

\footnotetext{
${ }^{6}$ The altruism parameter $\beta$ can thus be rewritten as $\beta=n \rho \hat{\beta}$, where $\hat{\beta}$ would denote the pure altruism factor per descendant.

${ }^{7}$ See Michel et al. (2006) for a comparison between different forms of altruism.
} 
of human capital $h_{t+1}^{i}$ of an adult individual belonging to dynasty $i$ and generation $t+1$ is entirely determined by his parent's investment $e_{t}^{i}$ in his education. Moreover, we consider a simple form of technological indivisibility in the production of human capital. In particular, the human capital level of an individual can take two values depending on whether his parent investment in his education is below or above the fixed cost of education $\mu$. Thus, the level of human capital at period $t+1$ of an adult individual belonging to dynasty $i$ who is born at period $t$ is given by the following equation:

$$
h_{t+1}^{i}=1+\Delta_{t+1}^{i},
$$

with

$$
\Delta_{t+1}^{i}= \begin{cases}0 & \text { if } e_{t}^{i}<\mu \\ \varepsilon & \text { if } e_{t}^{i} \geq \mu,\end{cases}
$$

where $\varepsilon>0$ and $\mu>0$. Obviously, the optimal investment in education for the individuals who want to have non-educated children (with $h_{t+1}^{i}=1$ ) is $e_{t}^{i}=0$, whereas those individuals who want educated children (with $h_{t+1}^{i}=1+\varepsilon$ ) will choose $e_{t}^{i}=\mu$. The number of efficiency units of labor supplied by an individual belonging to dynasty $i$ and generation $t$ is equal to his level $h_{t}^{i}$ of human capital.

There is a single commodity that can be devoted to either consumption or investment, and the investment can be either in physical or in human capital. Adult individuals distribute their income, which is composed of wage earnings plus the amount inherited from their parents, between consumption, investment in education of their children, and saving. Thus, the budget constraint faced by an adult individual belonging to dynasty $i$ and generation $t$ is

$$
\left(1-\tau_{w}\right) w_{t} h_{t}^{i}+\left(1-\tau_{b}\right) b_{t}^{i}=c_{t}^{i}+s_{t}^{i}+\left(1-s_{e}\right) n e_{t}^{i}+\lambda,
$$

where $s_{t}^{i}$ is the amount saved by this individual, $\lambda$ is the lump-sum tax faced by an adult individual, and $s_{e} \in[0,1)$ is the subsidy rate on education spending. The left hand side of (4) is the after tax income of the adult individual under consideration. When individuals are old, they receive a return on their saving, which is distributed between consumption and bequest for their children. Therefore, the budget constraint at period $t+1$ of an old individual of dynasty $i$ and generation $t$ (i.e., born at period $t-1)$ will be

$$
\left[1+\left(1-\tau_{k}\right) r_{t+1}\right] s_{t}^{i}-\theta=x_{t+1}^{i}+n b_{t+1}^{i},
$$

where $r_{t}$ is the before-tax rate of return on saving at period $t, \tau_{k} \in[0,1]$ is the tax rate on capital income, and $\theta$ is the lump-sum tax faced by an old individual. The values of the tax rates and of the amounts of lump sum taxes are assumed to be such that the smallest possible present value of individual lifetime income is positive,

$$
\left(1-\tau_{w}\right) w_{t}-\lambda-\frac{\theta}{1+\left(1-\tau_{k}\right) r_{t+1}}>0 .
$$

We also impose the constraint that parents cannot force their children to give them gifts when they (the parents) are old,

$$
b_{t+1}^{i} \geq 0 .
$$

Note that negative voluntary bequests will never arise in equilibrium given our assumption of one-sided altruism (from parents to children). 
Since individual preferences are assumed to be logarithmic, when parents do not invest in the education of their offspring, they leave a strictly positive amount of bequest. This is a technical implication of the Inada condition as the after-tax contribution $I_{t+1}^{i}$ to the future lifetime income of each of their children must be strictly positive. However, very poor individuals will leave a very small amount of bequest and obviously they will not invest at all in the education of their children as they cannot afford the fixed cost of education. Moreover, the strict positiveness of the after tax contribution $I_{t+1}^{i}$ is also compatible with the existence of parents investing in education but leaving no physical bequests.

In this economy there is a government that selects the different tax and subsidy rates and that spends the corresponding net revenue to finance its own consumption. The government faces a balanced budget constraint in each period so that it is subject to the following constraint at period $t$ :

$$
n \times\left[\int_{[0,1]}\left(\tau_{w} w_{t} h_{t}^{i}+\tau_{b} b_{t}^{i}-s_{e} n e_{t}^{i}+\lambda\right) d i\right]+\int_{[0,1]}\left(\tau_{k} r_{t} s_{t-1}^{i}+\theta\right) d i=G_{t},
$$

where $G_{t}$ denotes average government consumption per old individual at period $t$. We assume that government consumption is unproductive and does not affect directly individuals' welfare. Since $G_{t}$ is endogenous, fiscal policy exhibits income effects at the individual and aggregate levels.

Let us assume that the good of this economy is produced by means of a production function displaying constant returns to scale on physical and human capital and that the stock of physical capital fully depreciates after one period. As firms behave competitively, they choose the ratio of physical to human capital, such that their marginal productivity equal the rental rates of both capitals. Since this small open economy features free mobility of physical capital, the interest rate is exogenously given at the constant international level $r>0$, which under constant returns to scale determines the value of the ratio of physical to human capital. The value of this ratio of capitals determines in turn the wage $w$ per efficiency unit of labor in equilibrium. Thus, $r_{t}=r$ and $w_{t}=w$ for all $t$.

\section{The individual problem}

In this section, we will solve the problem that a generic individual belonging to dynasty $i$ and generation $t$ faces in order to choose the levels of consumption at adult and old ages and the transfers to his immediate descendants. Note first that the amount that an individual receives as inheritance and his level of human capital are the state variables determining his optimal choice. ${ }^{8}$ Thus, an individual belonging to dynasty $i$ and generation $t$ maximizes (1) with respect to $\left\{c_{t}^{i}, x_{t+1}^{i}, e_{t}^{i}, b_{t+1}^{i}\right\}$ subject to (2), (3), (4), (5), (6) and the non-negative constraints $c_{t}^{i} \geq 0$ and $x_{t+1}^{i} \geq 0$, by taking as given the amount $b_{t}^{i}$ inherited from his parent and his level $h_{t}^{i}$ of human capital as well as the rental prices for labor and capital. Recall that in this intertemporal maximization problem, the optimal value of the control variable $e_{t}^{i}$ will be either zero or $\mu$ because of the functional form adopted by the technology producing human capital. Thus, we

\footnotetext{
${ }^{8}$ Human capital is a state variable because the individuals' education was decided and financed by their parents.
} 
will solve the individual problem by following a two-stage procedure: first, we take the value of $e_{t}^{i}$ as given, and then solve for the amounts of saving $s_{t}^{i}$ and bequest $b_{t+1}^{i}$; and second, we find the optimal amount of $e_{t}^{i}$ given the values of $s_{t}^{i}$ and $b_{t+1}^{i}$ obtained in the previous stage.

We now proceed by presenting the details of the solution procedure. From the first order conditions of the individual problem, we obtain in Appendix A the following optimality conditions:

$$
x_{t+1}^{i}=\rho R\left(\tau_{k}\right) c_{t}^{i},
$$

and

$$
\frac{\beta\left(1-\tau_{b}\right)}{I_{t+1}^{i}} \leq \frac{n(1+\rho)}{R\left(\tau_{k}\right)\left[\left(1-\tau_{w}\right) w h_{t}^{i}+\left(1-\tau_{b}\right) b_{t}^{i}-n\left(1-s_{e}\right) e_{t}^{i}-\frac{n b_{t+1}^{i}}{R\left(\tau_{k}\right)}-\Omega\right]},
$$

with

$$
\Omega=\lambda+\frac{\theta}{R\left(\tau_{k}\right)},
$$

where the condition (9) holds with equality if $b_{t+1}^{i}>0$, and where $R\left(\tau_{k}\right)$ will denote from now on the after-tax gross rate of return on saving, i.e., $R\left(\tau_{k}\right)=1+\left(1-\tau_{k}\right) r>0$. Equation (8) yields the optimal allocation of consumption along the lifetime of an individual belonging to dynasty $i$ and generation $t$. Equation (9) characterizes the optimal amount of bequest. This condition tells us that, when the bequest $b_{t+1}^{i}$ is positive, the marginal variation in the utility of parents arising from a larger amount of bequest must be equal to zero. On the one hand, the right hand side of this equation is the utility loss experienced by the individual from the decrease in his lifetime income devoted to own consumption due to a marginal increase in the amount of bequest left to their children. On the other hand, the left hand side of (9) is the utility gain obtained by the individual from the marginal contribution of his bequest to the future lifetime income of their children.

Combining (8) with the budget constraints (4) and (5), we can derive the amount $s_{t}^{i}$ of saving as a function of the amount of intergenerational transfers. Thus, we obtain the following expression:

$$
s_{t}^{i}=\frac{1}{(1+\rho)}\left[\rho\left[\left(1-\tau_{w}\right) w h_{t}^{i}+\left(1-\tau_{b}\right) b_{t}^{i}-n\left(1-s_{e}\right) e_{t}^{i}-\lambda\right]+\frac{n b_{t+1}^{i}+\theta}{R\left(\tau_{k}\right)}\right] .
$$

Moreover, from (9) we can also compute the optimal amount of bequest that parents leave to their children when the constraint (6) is not binding, i.e., when $b_{t+1}^{i}>0$. By taking the condition (9) with equality, we directly obtain $b_{t+1}^{i}$ as a function of the investment in the education of children $e_{t}^{i}$ and of the endowments $b_{t}^{i}$ and $h_{t}^{i}$, i.e.,

$$
\begin{aligned}
b_{t+1}^{i} & \equiv B\left(b_{t}^{i}, h_{t}^{i}, e_{t}^{i}\right) \\
& =\left[\frac{\beta}{n(1+\rho+\beta)}\right]\left\{R\left(\tau_{k}\right)\left[\left(1-\tau_{w}\right) w h_{t}^{i}+\left(1-\tau_{b}\right) b_{t}^{i}-\left(1-s_{e}\right) n e_{t}^{i}-\Omega\right]\right. \\
& \left.-\left[\frac{n(1+\rho)\left(1-\tau_{w}\right)}{\beta\left(1-\tau_{b}\right)}\right] w \Delta_{t+1}^{i}\right\} .
\end{aligned}
$$


In the second stage of our solution procedure we will choose the investment in education $e_{t}^{i}$ that solves the individual's problem. Since the investment in education is indivisible, individuals must actually decide whether they invest $\mu$ units of income or do not invest at all. Observe that this decision is subject to the following restrictions. First, a positive investment in education for individuals with low levels of income may imply a negative optimal amount of bequest, which is not allowed in our economy by assumption. In this case, individuals will not invest in the education of their children. Therefore, the investment in education will be possible only if the individuals' income is sufficiently large so that this investment does not force individuals to leave a negative bequest. Second, if the amount $b_{t+1}^{i}$ of bequest is positive when the individual invests $\mu$ units of income in the education of their children, we have to check that this amount $\mu$ is in fact the optimal amount $e_{t}^{i}$ of investment in education. We next analyze these two issues separately.

\subsection{Optimal investment in education}

Let us first assume that the individual has a sufficiently large level of income so that the optimal amount $b_{t+1}^{i}$ of bequest is positive even when he decides to invest in the education of his children. We will now analyze whether to invest in education is an

optimal decision in this case. In Appendix A we obtain that the optimal levels $c_{t}^{i}$ and $x_{t+1}^{i}$ of consumption are given by

$$
\begin{gathered}
c_{t}^{i}=\left[\frac{n}{\beta\left(1-\tau_{b}\right) R\left(\tau_{k}\right)}\right] I_{t+1}^{i}, \\
x_{t+1}^{i}=\left[\frac{n \rho}{\beta\left(1-\tau_{b}\right)}\right] I_{t+1}^{i},
\end{gathered}
$$

when (6) is not binding, i.e., when $b_{t+1}^{i}>0$. Observe that conditions (12) and (13) yield the optimal levels $c_{t}^{i}$ and $x_{t+1}^{i}$ as increasing functions of $I_{t+1}^{i}$. Therefore, the choice of education investment that maximizes the utility (1) at period $t$ is the one that maximizes the contribution of parents to the future income of their children, $I_{t+1}^{i}$. Since the investment in education is indivisible, individuals must actually decide whether they invest $\mu$ units of income or do not invest at all. An individual will be willing to invest in the education of their children if and only if this action increases the after-tax lifetime income of their offspring. Thus, in order to find the optimal education decision we must compare the benefit of investing in education with the associated opportunity cost.

Note that an adult individual at period $t$ can either invest the amount $\mu$ in the education of his children or save this amount in order to leave a larger bequest in the next period. On the one hand, if he decides to invest in the education of their offspring, he must spend $\left(1-s_{e}\right) \mu$ units of income per child because $\mu$ is the cost of education and the government subsidizes the investment in education at the rate $s_{e}$. We obtain from (3) that this investment in education raises the after-tax lifetime income of each child by $\left(1-\tau_{w}\right) w \varepsilon$ units. On the other hand, if that individual decides to save the amount $\left(1-s_{e}\right) \mu$ in order to make a physical transfer to his children in the next period, then the after-tax lifetime income of the latter will increase by $\left(1-\tau_{b}\right)\left(1-s_{e}\right) \mu R\left(\tau_{k}\right)$ units since $R\left(\tau_{k}\right)$ is the after-tax return on saving. Therefore, an individual born at $t-1$ would like to invest in the education of his children at period $t$ if and only if the following condition holds:

$$
\left(1-\tau_{w}\right) w \varepsilon>\left(1-\tau_{b}\right)\left(1-s_{e}\right) \mu R\left(\tau_{k}\right) .
$$


From the previous equation we see that the optimality of investing in education does not depend on the individual's choices, but on the aggregate variables of the economy. We also observe that the optimality of investing in the education of children depends on fiscal policy. From condition (14), we directly obtain that the inheritance tax, the capital income tax and the education subsidy raise the willingness of individuals to invest in the education of their direct descendants, whereas the labor income tax reduces this willingness.

When the inequality in condition (14) is reversed, individuals adopt the corner solution $e_{t}^{i}=0$. From now on we will assume that condition (14) holds. Under this condition individuals will invest in the education of their offspring if they can afford the minimum after-tax cost of education given by $\left(1-s_{e}\right) \mu$. Note however that, even when condition (14) holds, individuals will not invest in the education of their children if this investment gives raise to a negative optimal amount of bequest. In the next subsection we derive the levels of income above which individuals invest in the education of their direct descendants.

\subsection{Human capital policy}

We are going to characterize the initial values of inheritance and human capital for which individuals decide to invest in their children education. Let us consider a generic marginal individual who has received the inheritance $b^{1}$, has the level $h_{t}$ of human capital, invests in his children human capital and for whom the non-negativity constraint on bequests is just binding. The first order condition with respect to bequests (9) for this individual is

$$
\frac{\beta\left(1-\tau_{b}\right)}{\left(1-\tau_{w}\right) w \varepsilon}=\frac{n(1+\rho)}{R\left(\tau_{k}\right)\left[\left(1-\tau_{w}\right) w h_{t}+\left(1-\tau_{b}\right) b^{1}-n\left(1-s_{e}\right) \mu-\Omega\right]}
$$

so that

$$
b^{1}=\frac{1}{1-\tau_{b}}\left\{\left(1-s_{e}\right) n \mu+\left(1-\tau_{w}\right) w\left[\frac{n(1+\rho) \varepsilon}{\beta\left(1-\tau_{b}\right) R\left(\tau_{k}\right)}-h_{t}\right]+\Omega\right\} .
$$

Note that, if the inheritance $b_{t}$ that this individual receives becomes larger than $b^{1}$ $\left(b_{t}>b^{1}\right)$, then he will leave strictly positive bequests $\left(b_{t+1}>0\right)$. If this marginal individual receives a bequest $b_{t}$ slightly smaller than $b^{1}$ and decides not to invest in their children education $\left(e_{t}=0\right)$, then the right hand side (RHS) of (15) changes marginally, since the bequest left will become now approximately equal to the capitalization of his previous expenditure in education,

$$
b_{t+1} \approx\left(1-s_{e}\right) \mu R\left(\tau_{k}\right)
$$

or, equivalently,

$$
\frac{n b_{t+1}}{R\left(\tau_{k}\right)} \approx n\left(1-s_{e}\right) \mu
$$

However, the left hand side (LHS) of (15) will increase non-marginally since

$$
\frac{\beta\left(1-\tau_{b}\right)}{I_{t+1}} \approx \frac{\beta\left(1-\tau_{b}\right)}{\left(1-\tau_{b}\right) b_{t+1}}=\frac{\beta}{\left(1-s_{e}\right) \mu R\left(\tau_{k}\right)}>\frac{\beta\left(1-\tau_{b}\right)}{\left(1-\tau_{w}\right) w \varepsilon}
$$


where the inequality comes from (14). Combining (15) and (16) we get

$$
\begin{aligned}
\frac{\beta\left(1-\tau_{b}\right)}{I_{t+1}} & >\frac{n(1+\rho)}{R\left(\tau_{k}\right)\left[\left(1-\tau_{w}\right) w h_{t}+\left(1-\tau_{b}\right) b_{t}-n\left(1-s_{e}\right) \mu-\Omega\right]} \\
& \approx \frac{n(1+\rho)}{R\left(\tau_{k}\right)\left[\left(1-\tau_{w}\right) w h_{t}+\left(1-\tau_{b}\right) b_{t}-\frac{n b_{t+1}}{R\left(\tau_{k}\right)}-\Omega\right]},
\end{aligned}
$$

so that the optimality condition on bequests (9) is violated. Therefore, it is not optimal for individuals getting the amount $b^{1}$ of inheritance to withdraw their investment in education when they face a marginal decrease in his inheritance.

Note that, if $b_{t}$ becomes marginally smaller than $b^{1}$ and the individual keeps investing in education and leaves no bequest, then equation (15) implies that

$$
\frac{\beta\left(1-\tau_{b}\right)}{\left(1-\tau_{w}\right) w \varepsilon}<\frac{n(1+\rho)}{R\left(\tau_{k}\right)\left[\left(1-\tau_{w}\right) w h_{t}+\left(1-\tau_{b}\right) b_{t}-n\left(1-s_{e}\right) \mu-\Omega\right]},
$$

so that the original optimality condition on bequests (9) is satisfied since $b_{t+1}=0$. Therefore, there is an interval of inheritances $\left(b^{0}, b^{1}\right]$ for which $e_{t}^{i}=\mu$ and $b_{t+1}=0$.

Let us compute the threshold value $b^{0}$ below which individuals do not invest in education. For this level $b^{0}$ of inheritance an individual is indifferent between leaving only bequest or making all the transfers in the form of education and leaving no bequest. Note that, in case of leaving only bequest, its amount is equal to the capitalized cost of education, $b_{t+1}=\left(1-s_{e}\right) \mu R\left(\tau_{k}\right)$, so that the optimality condition on bequests (9) for this individual becomes

$$
\underbrace{\frac{\beta}{\left(1-s_{e}\right) \mu R\left(\tau_{k}\right)}}_{\frac{\beta\left(1-\tau_{b}\right)}{\left(1-\tau_{b}\right)_{t+1}}}=\frac{n(1+\rho)}{R\left(\tau_{k}\right)\left[\left(1-\tau_{w}\right) w h_{t}+\left(1-\tau_{b}\right) b^{0}-n\left(1-s_{e}\right) \mu-\Omega\right]} .
$$

Then,

$$
b^{0}=\frac{1}{1-\tau_{b}}\left[\frac{n(1+\rho+\beta)\left(1-s_{e}\right) \mu}{\beta}-\left(1-\tau_{w}\right) w h_{t}+\Omega\right] .
$$

It is then obvious from (14) that $b^{1}>b^{0}$. Observe also that the difference between these two thresholds depends on how large is the contribution of investing in education to the offspring's lifetime income relative to the contribution of leaving the fixed cost of education as a bequest. Any real shock or any variation in fiscal policy altering this relative contribution will change the mass of individuals who have access to education. This is in stark contrast with the related previous literature, where the parents derive utility not from their contribution to their descendants' income, but directly from the size of the intergenerational transfer (see, Galor and Zeira, 1993). In fact, this literature obtains that the transfer is a strictly monotonic increasing function of parents' wealth. However, this is not the case in our model because those individuals who have received an inheritance between $b^{0}$ and $b^{1}$ give the same transfer to their children: they invest the amount $\left(1-s_{e}\right) \mu$ in education and leave no bequest.

Note that the values $b^{0}$ and $b^{1}$ vary depending on whether the individual who has received these amounts of inheritance is educated or not. Thus, let us define $\widehat{b}^{j}=b^{j}$ when $h_{t}=1+\varepsilon$ and $\widetilde{b}^{j}=b^{j}$ when $h_{t}=1, j=0,1$. Moreover, we immediately obtain 
that $\widetilde{b}^{j}>\widehat{b}^{j}$, for $j=0,1$. Since the labor income of educated individuals is larger than that of non-educated, the threshold amount of inheritance above which parents are willing to pay for the education of their children is smaller for educated parents.

As we have just argued, the previous threshold values $\widetilde{b}^{0}$ and $\widehat{b}^{0}$ drive the dynamics of the human capital level within each dynasty. In particular, the dynamics of human capital inside a dynasty is given by the following dynamic equation:

$$
h_{t+1}^{i}=\left\{\begin{array}{l}
1 \text { if either } h_{t}^{i}=1 \text { and } 0 \leq b_{t}^{i}<\widetilde{b}^{0} \text { or } h_{t}^{i}=1+\varepsilon \text { and } 0 \leq b_{t}^{i}<\widehat{b}^{0} \\
1+\varepsilon \text { if either } h_{t}^{i}=1 \text { and } b_{t}^{i} \geq \widetilde{b}^{0} \text { or } h_{t}^{i}=1+\varepsilon \text { and } b_{t}^{i} \geq \widehat{b}^{0}
\end{array}\right.
$$

In our economy, when individuals do not invest in the education of their offspring, they always leave a strictly positive amount of bequest. This follows from the fact that the utility function (1) satisfies the Inada condition at origin with respect to the parents contribution to the lifetime income of their children $I_{t+1}^{i}$, that is, the marginal utility with respect to $I_{t+1}^{i}$ goes to infinity when this contribution tends to zero.

From the threshold levels $\left(\widetilde{b}^{0}, \widehat{b}^{0}, \widetilde{b}^{1}, \widehat{b}^{1}\right)$ of bequest defined in this section and equation (11), we get the following equation characterizing the dynamics of bequests within a dynasty:

$$
b_{t+1}^{i}=\left\{\begin{array}{l}
0 \text { if either } h_{t}^{i}=1 \text { and } \widetilde{b}^{0} \leq b_{t}^{i}<\widetilde{b}^{1} \text { or } h_{t}^{i}=1+\varepsilon \text { and } \widehat{b}^{0} \leq b_{t}^{i}<\widehat{b}^{1} \\
B^{1}\left(b_{t}^{i}\right) \text { if } h_{t}^{i}=1 \text { and } 0 \leq b_{t}^{i}<\widetilde{b}^{0} \\
B^{2}\left(b_{t}^{i}\right) \text { if } h_{t}^{i}=1 \text { and } b_{t}^{i}>\widetilde{b}^{1} \\
B^{3}\left(b_{t}^{i}\right) \text { if } h_{t}^{i}=1+\varepsilon \text { and } 0 \leq b_{t}^{i}<\widehat{b}^{0} \\
B^{4}\left(b_{t}^{i}\right) \text { if } h_{t}^{i}=1+\varepsilon \text { and } b_{t}^{i}>\widehat{b}^{1}
\end{array}\right.
$$

where the expressions $B^{1}\left(b_{t}^{i}\right) \equiv B\left(b_{t}^{i}, 1,0\right), B^{2}\left(b_{t}^{i}\right) \equiv B\left(b_{t}^{i}, 1, \mu\right), B^{3}\left(b_{t}^{i}\right) \equiv B\left(b_{t}^{i}, 1+\varepsilon, 0\right)$, and $B^{4}\left(b_{t}^{i}\right) \equiv B\left(b_{t}^{i}, 1+\varepsilon, \mu\right)$ are given in (11).

The dynamic equations (19) and (20) fully describe the policy functions for human capital and bequest, respectively, within a dynasty when condition (14) holds. In other words, these two equations drive the amount of human capital and bequest for the next cohort of the dynasty given the human capital and bequest of the present cohort.

\section{The dynamics of dynastic income}

In this section we study the dynamics of the joint distribution of bequest and human capital. Under our assumptions, the evolution of these two variables is governed by the dynamic equations (19) and (20). Since we have considered a small open economy, the evolution of each dynasty does not depend on the aggregate distribution. Thus, in this section we analyze the evolution of bequest and human capital for a given dynasty along time. Individuals within a cohort differ in two respects: first, individuals have different levels of income in their second period of life since they have received different 
transfers form their parents; and, second, individuals also differ in the composition of income due to the different composition of the transfers received from their parents. Thus, the amount that a dynasty initially receives as inheritance and the initial level of human capital fully drive the entire posterior path of bequest, human capital, and income.

\subsection{Stationary distribution of income}

We will now characterize the stationary distribution of bequest and human capital. For that purpose, we will prove that the dynamic system composed of equations (19) and (20) has at most two stationary solutions. We will see that there are three candidates for these steady states: a corner solution, where the amount of bequest is zero; and two interior (or strictly positive) solutions where the amount of bequests are given by the two possible fixed points of (20), which we will denote by $\bar{b}^{1}$ and $\bar{b}^{2}$. The point $\bar{b}^{1}$ is a fixed point of $B^{1}\left(b_{t}^{i}\right)$, whereas $\bar{b}^{2}$ is a fixed point of $B^{4}\left(b_{t}^{i}\right)$. Thus, we get from (11) that

$$
\bar{b}^{1}=\frac{\beta R\left(\tau_{k}\right)\left[\left(1-\tau_{w}\right) w-\Omega\right]}{n(1+\rho+\beta)-\beta R\left(\tau_{k}\right)\left(1-\tau_{b}\right)},
$$

and

$$
\bar{b}^{2}=\frac{\beta R\left(\tau_{k}\right)\left[\left(1-\tau_{w}\right) w(1+\varepsilon)-\left(1-s_{e}\right) n \mu-\frac{n(1+\rho)\left(1-\tau_{w}\right) w \varepsilon}{\beta R\left(\tau_{k}\right)\left(1-\tau_{b}\right)}-\Omega\right]}{n(1+\rho+\beta)-\beta R\left(\tau_{k}\right)\left(1-\tau_{b}\right)} .
$$

Obviously, a necessary condition for an amount of bequest being an interior steady state is that an educated (non-educated) parent who has received this level of inheritance does (not) actually invest in the education of their children. We will see next that the fixed points of the functions $B^{2}\left(b_{t}^{i}\right)$ and $B^{3}\left(b_{t}^{i}\right)$ cannot be stationary values of bequest. In order to prove that a fixed point $\bar{b}$ of $B^{2}\left(b_{t}^{i}\right)$ is not a steady state for bequest, let us assume that $b_{t}^{i}=\bar{b}>\widetilde{b}^{0}$ and $h_{t}^{i}=1$. As follows from (19) and (20), this individual leaves a bequest per capita equal to $b_{t+1}^{i}=B^{2}(\bar{b})=\bar{b}$ and invests in the education of their children so that $h_{t+1}^{i}=1+\varepsilon$. Thus, a son of the previous individual will enjoy an endowment vector $\left(h_{t+1}^{i}, b_{t+1}^{i}\right)$ equal to $(1+\varepsilon, \bar{b})$ so that he will also invest in the education of their children and will leave them a bequest equal to $b_{t+2}^{i}=B^{4}(\bar{b}) \neq \bar{b} .{ }^{9}$ This proves that the fixed point of $B^{2}\left(b_{t}^{i}\right)$ is not a steady state because it is not a rest point of the dynamic equation (19).

We can follow similar arguments to prove that a fixed point $\bar{b}$ of $B^{3}\left(b_{t}^{i}\right)$ cannot be a steady state. For this purpose, assume that $b_{t}^{i}=\bar{b}<\widehat{b}^{0}$ and $h_{t}^{i}=1+\varepsilon$. As follows from (19) and (20), this individual leaves a bequest per capita equal to $b_{t+1}^{i}=B^{3}(\bar{b})=\bar{b}$. However, he does not invest in the education of their children so that $h_{t+1}^{i}=1$. Thus, a son of the previous individual will enjoy an endowment $\left(h_{t+1}^{i}, b_{t+1}^{i}\right)$ equal to $(1, \bar{b})$ and, thus, he will not invest either in the education of their children and will leave them a bequest equal to $b_{t+2}^{i}=B^{1}(\bar{b}) \neq \bar{b} .{ }^{10}$ This proves in turn that the fixed point of $B^{3}\left(b_{t}^{i}\right)$ is not a rest point of the dynamic equation (19).

As a summary, we conclude that mobility in human capital across generations prevents the fixed points of $B^{2}\left(b_{t}^{i}\right)$ and $B^{3}\left(b_{t}^{i}\right)$ from being steady states for bequest. However, by the same reason, the fixed points of $B^{1}\left(b_{t}^{i}\right)$ and $B^{4}\left(b_{t}^{i}\right)$ may be steady states. The amount $\bar{b}^{1}$ of bequest is stationary because those non-educated individuals who

\footnotetext{
${ }^{9}$ As $\bar{b}>\widetilde{b}^{0}$ and $\widetilde{b}^{0}>\widehat{b}^{0}$ then $\bar{b}>\widehat{b}^{0}$, which together with $h_{t+1}=1+\varepsilon$ implies that $b_{t+2}^{i}=B^{4}(\bar{b})$.

${ }^{10}$ As $\bar{b}<\widehat{b}$ and $\widetilde{b}>\widehat{b}$ then $\bar{b}<\widetilde{b}$, which together with $h_{t+1}=1$ implies that $b_{t+2}^{i}=B^{1}(\bar{b})$.
} 
have received this level of inheritance do not invest in the education of their children, whereas $\bar{b}^{2}$ is a stationary amount of bequest since the educated individuals who have received this level of inheritance do finance the education of their offspring.

Observe that $\bar{b}^{1}$ can be either smaller or larger than $\bar{b}^{2}$. In the first case the educated individuals leave a larger amount of bequest to their children than the non-educated, whereas the opposite is true in the second case. By using (21) and (22), we obtain that $\bar{b}^{1}<\bar{b}^{2}$ if and only if

$$
\left(1-\tau_{w}\right) w \varepsilon-\left(1-s_{e}\right) n \mu-\frac{n(1+\rho)\left(1-\tau_{w}\right) w \varepsilon}{\beta\left(1-\tau_{b}\right) R\left(\tau_{k}\right)}>0
$$

The left-hand side of (23) collects the three forces driving the relationship between $\bar{b}^{1}$ and $\bar{b}^{2}$. This relationship depends first on how large is the labor income of educated parents with respect to the income of non-educated parents (the education premium $\varepsilon$ ). Second, the education cost $\mu$ reduces the amount of bequest that the parents investing in education are willing to leave to their children. Finally, the third term shows that the larger is the contribution of education to the labor income of children, the smaller is the amount of bequest that educated parents must leave to achieve the optimal amount of the contribution to the future income of their children. Note that in order to satisfy condition (23) we must have

$$
\frac{n(1+\rho)}{\beta\left(1-\tau_{b}\right) R\left(\tau_{k}\right)}<1
$$

If the previous inequality holds, then condition (23) is fulfilled whenever the school premium $\varepsilon$ is sufficiently large relative to the indivisible cost $\mu$ of education. In this case educated parents enjoy enough income to provide education to their children and endow them with a large amount of initial wealth. However, non-educated parents neither invest in their children's education nor leave a large amount of bequest. Note in this respect that several empirical studies provide evidence supporting the existence of a large education premium (see, e.g., Bound and Johnson, 1992; or Barro and Lee, 2001), and document a dramatic increase in this premium from the middle of the past century (see, e.g., Autor et al., 1998). For instance, Barro and Lee (2001) estimate that the wage of individuals who have completed the higher level of education relative to those with an incomplete primary level is around 2.46 .

In order to simplify the exposition and keep the length of the paper within a reasonable bound, we will only analyze the dynamics of the more empirically plausible case where $\bar{b}^{1}<\bar{b}^{2}$. In this respect Nordblom and Ohlsson (2011) estimate that the education level of parents in Sweden increases the probability that they transfer both human and physical capital to their children. That is, intergenerational transfers of human capital and physical wealth are complements in equilibrium. Therefore, we will assume that (23) holds from now on. ${ }^{11}$

We are interested in those parameter configurations for which the two interior steady states for bequest $\bar{b}^{1}$ and $\bar{b}^{2}$ exist and are locally stable. In this case, the economy exhibits heterogeneity among individuals at the stationary distribution and,

\footnotetext{
${ }^{11}$ The analysis of the case with $\bar{b}^{1}>\bar{b}^{2}$ becomes just a mechanical exercise that replicates the same arguments that we will use in the rest of the paper for the case under consideration. In this case (i.e., when (23) does not hold), we must also impose that $B^{4}(0)>0$ to ensure the existence of a two-point interior stationary distribution.
} 
thus, we can analyze how the initial composition of the intergenerational transfers and the fiscal policy parameters affect income inequality and human capital mobility. In order to establish the existence and local stability of $\bar{b}^{1}$ and $\bar{b}^{2}$, we must impose some assumptions on the fundamentals of our economy. In particular, the existence and local stability of the stationary amounts of bequest depend on whether the non-negative constraint on bequests (6) is binding or not.

First, the existence of two interior and locally stable fixed points $\bar{b}^{1}$ and $\bar{b}^{2}$ requires the functions $B^{j}\left(b_{t}^{i}\right)$ in $(20)$ to satisfy $B^{1}(0)>0$ and $B^{4}(0)>0$ and to exhibit a slope smaller than one for all $j=1,2,3,4$. On the one hand, as was pointed in the previous section, the Inada condition of the utility function (1) with respect to $I_{t+1}^{i}$ ensures that $B^{1}\left(b_{t}^{i}\right)>0$ for all $b_{t}^{i} \geq 0$. Moreover, the condition (23) ensures that $B^{4}\left(b_{t}^{i}\right)>B^{1}\left(b_{t}^{i}\right)$ for all $b_{t}^{i} \geq 0$ so that, in this case, it is also true that $B^{4}(0)>0$ and, hence, $\widehat{b}^{1}<0$. On the other hand, given these properties, interior fixed points exist if and only if the functions $B^{j}\left(b_{t}^{i}\right)$ have slope smaller than one. This property of $B^{j}\left(b_{t}^{i}\right)$ holds under the following condition:

$$
\frac{\beta\left(1-\tau_{b}\right) R\left(\tau_{k}\right)}{n(1+\rho+\beta)}<1
$$

which also ensures the local stability of the interior steady states $\bar{b}^{1}$ and $\bar{b}^{2}$. The previous condition imposes the standard upper bound on the the return from capital so as to prevent the size of bequests within a dynasty to grow unboundedly. Combining (25) and (24) we obtain the following restriction on the net of taxes gross rate of return:

$$
\frac{n(1+\rho)}{\beta\left(1-\tau_{b}\right)}<R\left(\tau_{k}\right)<\frac{n(1+\rho+\beta)}{\beta\left(1-\tau_{b}\right)}
$$

Second, since $B^{4}(0)>0$ and condition (25) holds, the interior steady state $\bar{b}^{2}$ exists. However, the existence of the interior steady state $\bar{b}^{1}$ requires that

$$
\bar{b}^{1} \leq \widetilde{b}^{0} .
$$

If (27) does not hold, the amount $\bar{b}^{1}$ of bequest could not be a steady state because the function $B^{1}\left(b_{t}^{i}\right)$ does not characterize the dynamics of bequest left by non-educated individuals who have received an inheritance larger than $\widetilde{b}^{0}$. Note that evaluating (18) for $h_{t}^{i}=1$ we obtain

$$
\widetilde{b}^{0}=\frac{1}{1-\tau_{b}}\left[\frac{n(1+\rho+\beta)\left(1-s_{e}\right) \mu}{\beta}-\left(1-\tau_{w}\right) w+\Omega\right] .
$$

Therefore, given the expressions for $\widetilde{b}^{0}$ and $\bar{b}^{1}$ in (28) and (21), respectively, condition (27) ends up being just the following condition on the fundamentals of the economy:

$$
w \leq \frac{1}{\left(1-\tau_{w}\right)}\left[\left(\frac{n(1+\rho+\beta)}{\beta}-\left(1-\tau_{b}\right) R\left(\tau_{k}\right)\right)\left(1-s_{e}\right) \mu+\Omega\right] .
$$

Note that, if $\Omega \geq 0$, then the right hand side of the previous inequality is strictly positive if (25) holds. Therefore, (27) is fulfilled whenever the wage $w$ of non-educated individuals is sufficiently small so that it does not enable them to invest in education. If the previous upper bound on $w$ were not met, then a dynasty initially composed of noneducated individuals will end up investing in education as the amount of inheritance will eventually become larger than the threshold value $\widetilde{b}^{0}$. 
From now on we will also assume that the conditions (23), (25), and (29) hold. It is important to mention that these three conditions are simultaneously met when the value of $R\left(\tau_{k}\right)$ satisfies the bounds given in (26), the wage $w$ per efficiency unit (or wage paid to non-educated workers) is sufficiently low (see (29)) and the school premium $\varepsilon$ relative to the education cost $\mu$ is sufficiently high (see (23)). Note that the latter condition allows the economy to fulfill the maintained assumption (14). When these conditions are met, our economy converges to a two-point distribution with appealing empirical properties. ${ }^{12}$ Under this stationary distribution, some dynasties leave a positive bequest to each of their children equal to $\bar{b}^{1}$ and do not invest in their education, whereas other dynasties do invest in the education of their children and leave a larger bequest per capita equal to $\bar{b}^{2}$. As we have already mentioned, this property of the stationary distribution agrees with the empirical evidence provided by Nordblom and Ohlsson (2011). The case under consideration is thus depicted in Figure 1, which plots the relationship between the bequest left to children and the inheritance received from parents given by the dynamic equation (20). Note that this relationship is piecewise linear.

\section{[Insert Figure 1]}

Since the initial distribution of bequest and human capital determines both the stationary income distribution and the intergenerational mobility in human capital, we will characterize in the following subsection the entire path of bequest and human capital for all types of dynasties when the economy converges to the aforementioned two-point distribution. We will use this analysis to study in the next sections the impact of fiscal policy in the distribution dynamics for an arbitrary initial distribution.

\subsection{Dynamic analysis}

In this subsection we analyze the dynamics of an economy that converges to the twopoint distribution having the steady-state values $\bar{b}^{1}$ and $\bar{b}^{2}$. As was shown in the previous subsection, this occurs when the conditions (23), (25), and (29) hold. We will next analyze how the initial distribution of bequest and human capital determines the number of dynasties converging to a situation with $h_{t}^{i}=1$ and $b_{t}^{i}=\bar{b}^{1}$ and those converging to another with $h_{t}^{i}=1+\varepsilon$ and $b_{t}^{i}=\bar{b}^{2}$.

We first observe that those dynasties whose members have the initial human capital $h_{t}^{i}=1$ and who have received an inheritance $b_{t}^{i}$ smaller than $\widetilde{b}^{0}$ converge to a steady state given by $h^{i}=1$ and $b^{i}=\bar{b}^{1}$, whereas all the dynasties with members having the initial human capital $h_{t}^{i}=1+\varepsilon$ converge to a steady state given by $h^{i}=1+\varepsilon$ and $b^{i}=\bar{b}^{2}$. This conclusion directly follows from the dynamics of human capital and bequest described by (19) and (20), and after using condition (25) ensuring the local stability of the steady states $\bar{b}^{1}$ and $\bar{b}^{2}$. On the one hand, the members of a dynasty with $h_{t}^{i}=1$ and $b_{t}^{i}$ smaller than $\widetilde{b}^{0}$ do not invest in the education of their children and leave a non-negative amount $b_{t+1}^{i}$ of bequest satisfying $b_{t+1}^{i}<\widetilde{b}^{0}$. On the other hand, the members of a dynasty with a level $h_{t}^{i}=1+\varepsilon$ of human capital always invest in the education of their children because $\widehat{b}^{0}<0$. Condition (25) ensures that the bequests of the former and the latter dynasties will converge to $\bar{b}^{1}$ and $\bar{b}^{2}$, respectively.

The members of the dynasties with $h_{t}^{i}=1$ and $b_{t}^{i}$ larger than $\widetilde{b}^{0}$ decide to finance the education of their children as dictated by equation (19). Moreover, the amount

\footnotetext{
${ }^{12}$ In Appendix B we present all possible configurations of the stationary distribution when at least one of the two conditions (25) and (27) does not hold.
} 
$b_{t+1}^{i}=B^{2}\left(b_{t}^{i}\right)$ of bequest that they leave is non-negative so that the children of those individuals will then decide to leave a bequest per capita equal to $b_{t+2}^{i}=B^{4}\left(b_{t+1}^{i}\right)$. The dynasty will thus converge to the steady state given by $h^{i}=1+\varepsilon$ and $b^{i}=\bar{b}^{2}$. Therefore, the threshold value $\widetilde{b}^{0}$ of bequest drives the dynamics of the initially noneducated dynasties and, in particular, their upward mobility in terms of human capital. The non-educated dynasties will converge to the steady state associated with $h^{i}=1+\varepsilon$ and $b^{i}=\bar{b}^{2}$ if their members are initially endowed with an inheritance $b_{t}^{i}$ larger than $\widetilde{b}^{0}$, whereas these non-educated dynasties with an inheritance $b_{t}^{i}$ smaller than $\widetilde{b}^{0}$ will converge to the steady state given by $h^{i}=1$ and $b^{i}=\bar{b}^{1}$. We can thus summarize the dynamic behavior of the economy considered in this subsection as follows:

Proposition 1 . The dynasties with an initial level $h_{0}^{i}=1$ of human capital will converge: (i) to the steady state with $h^{i}=1$ and $b^{i}=\bar{b}^{1}$ if their initial level $b_{0}^{i}$ of inheritance is such that $b_{0}^{i}<\widetilde{b}^{0}$; and (ii) to the steady state with $h^{i}=1+\varepsilon$ and $b^{i}=\bar{b}^{2}$ if $b_{0}^{i}>\widetilde{b}^{0}$. The dynasties with an initial level $h_{0}^{i}=1+\varepsilon$ of human capital will always converge to the steady state with $h^{i}=1+\varepsilon$ and $b^{i}=\bar{b}^{2}$.

We have thus shown how the initial distribution of bequest and human capital determines the stationary distribution of these variables and thus the stationary distribution of income. In particular, our model predicts that the propensity to invest in the education of children depends positively on the education level of parents. With respect to human capital mobility, we observe that only the non-educated dynasties may experience intergenerational mobility so that only upward mobility is possible in our economy. In particular, the dynasties with an initial level $h_{0}^{i}=1$ of human capital educate their children in the first period if $b_{0}^{i}>\widetilde{b}^{0}$, and then they remain as educated dynasties forever. Therefore, for these dynasties the human capital adjusts instantaneously to the level $1+\varepsilon$ and the amount of bequest converge monotonously along time to the steady state $\bar{b}^{2}$. Moreover, the threshold $\widetilde{b}^{0}$ in (28) contains all the information about the determinants of this one-shot upward mobility.

\section{Effects of fiscal policy on the stationary distribution}

In this section we will analyze how fiscal policy affects the stationary distribution towards which an economy converges given an initial distribution. We will assume a parametric configuration ensuring that the economy converges to the empirically plausible two-point distribution considered in Subsection 4.2. Given an initial distribution of bequest and human capital, we will study how non-anticipated permanent marginal shocks on the fiscal parameters alter this stationary distribution. In particular, we will develop balanced-budget incidence analyses where government consumption will accommodate the permanent fiscal shocks in order to satisfy the constraint (7).

Fiscal policy can alter the stationary amounts $\bar{b}^{1}$ and $\bar{b}^{2}$ of bequest and can also affect the proportion of dynasties converging to each of these steady states by distorting the intergenerational mobility in human capital. The distance between $\bar{b}^{1}$ and $\bar{b}^{2}$ provides information on the distribution of income between educated and non-educated adult individuals due to the different amounts of inheritance they receive. Obviously, the effects of fiscal policy on the distance between $\bar{b}^{1}$ and $\bar{b}^{2}$ is not a measure of the effects on income inequality, as these policies also modify the long run relative 
frequencies of the two groups. These relative frequencies are obtained from the longrun fraction $\alpha$ of individuals who are not educated and do not provide education to their descendants. This long-run fraction depends on the initial distribution of inheritance among the non-educated individuals and the initial fraction of non-educated individuals. Let $\alpha_{0} \in(0,1)$ be the initial fraction of non-educated individuals and assume that inheritances among the non-educated are initially distributed according to the continuous distribution function $F$ with $F(b)=0$ for $b<0$. Therefore, a fraction $F\left(\widetilde{b}_{0}\right)$ of non-educated individuals will not educate their children. This implies that a fraction $\alpha=\alpha_{0} F\left(\widetilde{b}_{0}\right)$ of individuals will not be educated in the long run. Note that $\alpha$ depends on the threshold value $\widetilde{b}_{0}$ and, thus, is an endogenous variable that could be modified by fiscal policy. The effect of fiscal policies on intergenerational upward mobility in human capital is then given by their impact on the threshold amount $\widetilde{b}^{0}$ of bequest. A smaller value of $\widetilde{b}^{0}$ means that the set of initial amounts of bequest for which non-educated dynasties end up being educated becomes larger. Moreover, as the wage $w$ and the skill premium $\varepsilon$ are both exogenous, an increase in the number of educated dynasties also increases the aggregate income of the economy. Therefore, the smaller is the value of $\widetilde{b}^{0}$, the easier is intergenerational upward mobility and the larger is aggregate income. ${ }^{13}$

The standard measure of income inequality is the Gini index, which in our two-point distribution is defined as

$$
\Gamma=1-\frac{q^{n}}{\alpha},
$$

where $q^{n}$ is the fraction of total income held by non-educated individuals,

$$
q^{n}=\frac{\alpha z^{n}}{\alpha z^{n}+(1-\alpha) z^{e}},
$$

$z^{n}$ is the net present income of non-educated individuals and $z^{e}$ is the net present income of educated individuals (see Checchi and García-Peñalosa, 2004). In order to perform the analysis of the effects of fiscal policy it is going to be convenient to rewrite the Gini index as

$$
\Gamma=1-\frac{1}{1+M}
$$

where $M=(1-\alpha) \Pi$ and

$$
\Pi=\frac{z^{e}-z^{n}}{z^{n}}=\left(\frac{\beta}{1+\rho+\beta}\right)\left(\frac{\varepsilon-\frac{\left(1-\tau_{b}\right) R\left(\tau_{k}\right)\left(1-s_{e}\right) \mu}{\left(1-\tau_{w}\right) w}}{1-\frac{\Omega}{\left(1-\tau_{w}\right) w}}\right)>0 .
$$

The Gini index is thus positively related with the variable $M$ which, therefore, provides also a measure of income inequality. If $M=0$ the distribution exhibits perfect equality and if $M=\infty$ the distribution is characterized by extreme inequality. This measure of income inequality depends on two variables: the long-run fraction of educated individuals, $1-\alpha$, and the relative difference $\Pi$ of income between educated and non-educated individuals, which is given by $\Pi .{ }^{14}$ Note that both variables depend

\footnotetext{
${ }^{13}$ Fscal policy can also affect the threshold level $\widehat{b}^{0}$. However, since we will only consider marginal shocks in fiscal policy, we can maintain the assumption that this threshold level remains negative after the fiscal shocks.

${ }^{14}$ Condition (14) implies that the numerator of $\Pi$ is positive and $b^{1}>0$ implies that the denominator is also positive.
} 
on fiscal policy parameters. Let $\tau_{i}$ be a given tax rate. Then, the effects of increasing this tax on our measure of income inequality are

$$
\frac{\partial M}{\partial \tau_{i}}=-\left(\frac{\alpha \psi \Pi}{\widetilde{b}_{0}}\right) \frac{\partial \widetilde{b}_{0}}{\partial \tau_{i}}+(1-\alpha) \frac{\partial \Pi}{\partial \tau_{i}}
$$

where

$$
\psi=\frac{F^{\prime}\left(\widetilde{b}_{0}\right) \widetilde{b}_{0}}{F\left(\widetilde{b}_{0}\right)}>0
$$

is the elasticity of the distribution function. As follows from this expression, the effects of fiscal policy on income inequality will be ambiguous when taxes increase (reduce) the proportion of educated individuals but reduce (increase) the relative difference of income between the two groups. In this case, the net effect on income inequality depends on (i) the shape of the distribution function, measured by its elasticity, and (ii) the fraction of non-educated individuals. When the distribution function is sufficiently inelastic or the fraction of non-educated individuals is sufficiently small, the change in the fraction of educated individuals will be small and the effects of fiscal policy on income inequality will be driven by the change in the relative difference of income between the two groups of individuals. In contrast, when the distribution function is sufficiently elastic or the fraction of non-educated individuals is sufficiently large, the effects of fiscal policy will be driven by the change in the fraction of educated individuals.

We next study separately the effect of each of the tax instruments under consideration.

\subsection{Inheritance taxation}

We will first show that the tax on inheritances reduces the stationary values $\bar{b}^{1}$ and $\bar{b}^{2}$ of bequest. Differentiating the function (11) with respect to $\tau_{b}$ we obtain

$$
\frac{\partial B\left(b_{t}^{i}, h_{t}^{i}, e_{t}^{i}\right)}{\partial \tau_{b}}=-\left[\frac{\beta R\left(\tau_{k}\right) b_{t}^{i}}{n(1+\rho+\beta)}+\frac{(1+\rho)\left(1-\tau_{w}\right) w \Delta_{t+1}^{i}}{(1+\rho+\beta)\left(1-\tau_{b}\right)^{2}}\right],
$$

which is clearly negative. Since the values $\bar{b}^{1}$ and $\bar{b}^{2}$ are fixed points of $B^{1}\left(b_{t}^{i}\right)=$ $B\left(b_{t}^{i}, 1,0\right)$ and $B^{4}\left(b_{t}^{i}\right)=B\left(b_{t}^{i}, 1+\varepsilon, \mu\right)$, respectively, the effects of the inheritance tax on these stationary solutions immediately follow from (32) and (3). Moreover, the marginal increase in the value of this tax rate reduces the gap between $\bar{b}^{1}$ and $\bar{b}^{2}$ because the negative impact of this permanent policy shock on $B^{4}\left(b_{t}^{i}\right)$ is larger than in $B^{1}\left(b_{t}^{i}\right)$ as follows from (32) after substituting the corresponding value of $\Delta_{t+1}^{i}$. Thus, the increase in the tax rate on inheritances reduces the stationary differences in the income per capita between educated and non-educated individuals. However, because of the strong reduction of the income of the non-educated individuals, the increase in this tax raises the relative difference of income between the two groups of individuals,

$$
\frac{\partial \Pi}{\partial \tau_{b}}=\left(\frac{\beta}{1+\rho+\beta}\right)\left(\frac{R\left(\tau_{k}\right)\left(1-s_{e}\right) \mu}{\left(1-\tau_{w}\right) w-\Omega}\right)>0 .
$$

We now analyze the effects of the tax on the threshold amount $\widetilde{b}^{0}$ of bequest, which determines the steady state towards which each dynasty converges to. Clearly, 
the value $\widetilde{b}^{0}$ given in (28) is strictly increasing in the tax $\tau_{b}$ on inheritances since $\widetilde{b}^{0}>0$. Therefore, the tax on inheritances reduces the number of initially non-educated dynasties converging to the steady state given by $h^{i}=1+\varepsilon$ and $b^{i}=\bar{b}^{2}$. As was expected from the dynamic analysis of the previous section, this tax does not alter the number of initially educated dynasties converging to the steady state given by $h^{i}=1+\varepsilon$ and $b^{i}=\bar{b}^{2}$.

The net effect of this tax on income inequality is ambiguous as this tax increases the fraction of non-educated individuals and raises the relative difference of income between the two groups of individuals,. The first effect reduces income inequality, whereas the second increases income inequality. The second effect dominates when either the distribution is inelastic or the value of $\alpha$ is sufficiently small. In this case, an increase in the tax rate on inheritances increases income inequality. Otherwise, an increase in this tax results in a reduction of income inequality.

The overall effects of inheritance taxation on the stationary distribution can then be summarized as follows. After an increase in this tax rate, the stationary fraction of non-educated individuals increases and the amount of bequest becomes smaller in the long run. This reduction in the amount of bequest is larger for the group of educated adult individuals (i.e., for the richest people). The aggregate adult income at the steady state then goes down. Therefore, all these effects of inheritance taxation translate into a reduction in both aggregate income and human capital accumulation. However, the final effect on income inequality is generally ambiguous. Figure 2 presents the change in the relative frequencies of the stationary distribution of bequests after an increase in the tax rate on inheritances.

\section{[Insert Figure 2]}

Inheritance taxes clearly make physical bequests more costly as an instrument to increase the lifetime income of children. This explains why an inheritance tax reduces the amount of bequest that parents leave to their offspring. Moreover, this distortion of the tax on the bequest's decision margin also explains why this tax raises the amount of inheritance that an individual must receive from his parents in order to be willing to invest in the education of their children. Therefore, an increase in the inheritance tax ends up being an impediment for upward mobility as the reduction in initial wealth prevents a larger fraction of individuals from jumping the hurdle associated to the indivisible cost of education.

\subsection{Labor income taxation}

To obtain the effects of labor income taxation, we use (11) to get

$$
\frac{\partial B\left(b_{t}^{i}, h_{t}^{i}, e_{t}^{i}\right)}{\partial \tau_{w}}=\left[\frac{\beta w R\left(\tau_{k}\right)}{n(1+\rho+\beta)}\right]\left[\frac{n(1+\rho) \Delta_{t+1}^{i}}{\beta\left(1-\tau_{b}\right) R\left(\tau_{k}\right)}-h_{t}^{i}\right] .
$$

By using (3), (20) and (24), we immediately get

$$
\frac{\partial B^{1}}{\partial \tau_{w}}<0 \text { and } \quad \frac{\partial B^{4}}{\partial \tau_{w}}<0 .
$$

Hence, a marginal increase in the rate of the labor income tax reduces the stationary amounts $\bar{b}^{1}$ and $\bar{b}^{2}$ of bequest. Moreover, by using condition (23) we also obtain that an 
increase in the rate of the labor income tax pushes the gap between the values $\bar{b}^{1}$ and $\bar{b}^{2}$ down. In other words, the labor income taxation reduces the stationary differences in the income per capita between educated and non-educated individuals. Moreover, if $\Omega$ is sufficiently small, this tax also reduces the relative difference $\Pi$ of income between the two groups of individuals as follows from using (30),

$$
\frac{\partial \Pi}{\partial \tau_{w}}=\left(\frac{\beta w}{1+\rho+\beta}\right)\left(\frac{\varepsilon \Omega-\left(1-\tau_{b}\right) R\left(\tau_{k}\right)\left(1-s_{e}\right) \mu}{\left[\left(1-\tau_{w}\right) w-\Omega\right]^{2}}\right)<0 .
$$

From (28), we get that the threshold value $\widetilde{b}^{0}$ is strictly increasing in the tax on labor income. Therefore, the labor income tax decreases the number of initially noneducated dynasties converging to the steady state given by $h^{i}=1+\varepsilon$ and $b^{i}=\bar{b}^{2}$. In this case, a positive permanent shock in the tax rate lowers the stationary fraction of population that is educated $\left(h^{i}=1+\varepsilon\right)$ and leaves a bequest equal to $\bar{b}^{2}$. Figure 2 illustrates also the change in the relative frequencies of the stationary distribution of bequests after an increase in the tax rate on labor income.

Summing up, an increase in the tax on labor income reduces income inequality because it increases the fraction of non-educated individuals and reduces the relative difference $\Pi$ of income between educated and non-educated individuals.

\subsection{Capital income taxation}

To obtain the effects of capital income taxation, we first get from (11) that

$$
\frac{\partial B\left(b_{t}^{i}, h_{t}^{i}, e_{t}^{i}\right)}{\partial \tau_{k}}=-\frac{\beta r\left[\left(1-\tau_{w}\right) w h_{t}^{i}+\left(1-\tau_{b}\right) b_{t}^{i}-n\left(1-s_{e}\right) e_{t}^{i}-\lambda\right]}{n(1+\rho+\beta)}
$$

Observe that the expression inside the square parenthesis in the RHS of (34) is the individual's disposable income at the adult age (see the budget constraint (4)). Hence, the derivative (34) is negative. Therefore, the tax on capital income reduces the stationary amounts $\bar{b}^{1}$ and $\bar{b}^{2}$ of bequest and, moreover, condition (23) implies that this reduction is larger for the amount $\bar{b}^{2}$ of bequest of educated individuals. However, the increase in this tax raises the relative difference $\Pi$ of income between the two groups of individuals,

$$
\frac{\partial \Pi}{\partial \tau_{k}}=\left(\frac{\beta}{1+\rho+\beta}\right)\left(\frac{\left(1-\tau_{b}\right) r\left(1-s_{e}\right) \mu}{\left(1-\tau_{w}\right) w-\Omega}\right)>0 .
$$

We clearly see from (28) that the marginal increase in the tax rate $\tau_{k}$ affects the threshold amount $\widetilde{b}^{0}$ of bequest only through its effect in the present value $\Omega$ of lumpsum taxation. An increase in the capital income tax $\tau_{k}$ involves a reduction in $R\left(\tau_{k}\right)$, which in turn increases (decreases) the present value $\Omega$ of lump-sum taxes if the lumpsum $\operatorname{tax} \theta$ paid by old individuals is positive (negative). Therefore, according to (28) an increase in $\tau_{k}$ results in a larger (smaller) threshold value of $\widetilde{b}^{0}$ if and only if $\theta>(<) 0$. Obviously, if the present value $\Omega$ of lump sum taxes increases, individuals will require a larger transfer from their parents to overcome this reduction in income to maintain their investment in education. In this case, capital income taxation makes human capital mobility more difficult.

When old individuals do not pay lump sum taxes, capital income taxation has no effect on human capital mobility. Clearly, the change in the after tax interest rate does not trigger any income effect when old individuals do not receive any exogenous 
income. Moreover, we easily see by looking at the optimality condition (17) of the marginal individual who is indifferent between leaving only bequest or making all the transfers in the form of education and leaving zero bequests that the tax rate $\tau_{k}$ affects symmetrically both the cost and the profit associated to their transfers. Note that for this individual the contribution to their descendants lifetime income is equal to the capitalized cost of education, $b_{t+1}=\left(1-s_{e}\right) \mu R\left(\tau_{k}\right)$, which appears in the LHS of (17), whereas the cost $n\left(1-s_{e}\right) \mu$ of his transfer, which appears in the denominator of the RHS, takes place when the individual is adult so that it has to be multiplied by $R\left(\tau_{k}\right)$ in order to obtain the cost in terms of consumption when old. Therefore, the resulting threshold value of $\widetilde{b}^{0}$ of bequest ends up being independent of the capital return $R\left(\tau_{k}\right)$ provided that $\theta=0$.

When $\theta=0$, the increase in the capital income tax does not modify the fraction of educated individuals but raises the relative difference $\Pi$ of income between between the two groups of individuals. Therefore, in this case, the capital income tax increases income inequality. This apparently surprising result arises because the increase in this tax reduces the opportunity cost of financing education and, obviously, this only benefits rich educated individuals.

\subsection{Education subsidies}

In this subsection, we analyze the effects of a marginal change in the subsidy to education investment. As before, government spending is adjusted endogenously so as to keep the government budget constraint balanced. Obviously, this policy can affect only the bequest left by those individuals who invest in the education of their children since only those individuals are entitled to receive the subsidy. In particular, an increase in the subsidy rate raises the disposable income of these individuals and does not alter their contribution to the lifetime income of their children. Hence, the subsidy stimulates the willingness of parents to leave bequest, which results in a reduction of the amount of inheritance that they must receive in order to invest in the education of their children. This conclusion can directly be proved by using (28) to see that $\widetilde{b}^{0}$ is strictly decreasing in the subsidy rate $s_{e}$. Observe that a permanent increase in the subsidy rate raises the stationary fraction of population that is educated $\left(h^{i}=1+\varepsilon\right)$ and leave bequest equal to $\bar{b}^{2}$ at the steady state. Moreover, the amount $\bar{b}^{2}$ of bequest left by each educated individual goes up, whereas the amount $\bar{b}^{1}$ of bequest left by non-educated (i.e., the poorest) individuals does not change. Therefore, the aggregate income of adult individuals rises at the steady state and, moreover, the proportion of aggregate income enjoyed by poorest adult individuals decreases. This implies that the relative difference $\Pi$ of income between the two groups raises as it follows from (30),

$$
\frac{\partial \Pi}{\partial s_{e}}=\left(\frac{\beta}{1+\rho+\beta}\right)\left(\frac{\left(1-\tau_{b}\right) R\left(\tau_{k}\right) \mu}{\left(1-\tau_{w}\right) w-\Omega}\right)>0 .
$$

Figure 3 illustrates the change in the relative frequencies of the stationary distribution of bequests after an increase in the subsidy rate on education.

$$
\text { [Insert Figure 3] }
$$

The increase in the rate of the education subsidy raises income inequality as it increases both the fraction of educated individuals and the relative difference $\Pi$ of 
income. This effect is not a surprising since this subsidy is given only to the group of rich educated individuals.

Before closing this subsection, we should note that an increase in the subsidy to education has an impact qualitatively similar to a reduction in the cost of education $\mu$ (see (28)). The parameter $\mu$ characterizes the technology for human capital accumulation as it determines the productivity of the education system, which is obviously a decreasing function of the education cost $\mu$. Therefore, a more productive education sector results in a larger upward mobility in human capital as there will be a larger fraction of population that becomes educated, and in a larger income inequality between educated and non-educated individuals (see Acemoglu, 2002).

\subsection{Social security system}

We now analyze the effect of a pay-as-you-go social security system where old individuals receive lump-sum benefits that are financed by the contributions of adult individuals. If the contributions of adult individuals take the form of labor income taxes, the social security system has two distortionary effects on our economy. On the one hand, since the labor supply in efficiency units is endogenous, the labor income tax distorts the individual choice as was showed in Subsection 5.2. On the other hand, the social security system implies an ex-ante intergenerational redistribution from adult to old individuals. Since we have already studied the distortionary effect of labor income taxation, we will exclusively focus on the effects of intergenerational redistribution achieved through lump-sum taxes. To do so, we consider a marginal variation of the lump-sum tax $\lambda$ satisfying

$$
\frac{d \theta}{d \lambda}=-n
$$

in order to fulfil the budget constraint (7). Therefore, we will assume that the government increases the lump-sum tax $\lambda$ paid by the adult individuals, and the additional revenues are entirely devoted to finance an increase in the lump-sum subsidy $\theta$ to the old individuals.

An increase in the lump-sum transfer from adult to old individuals (an increase in $\lambda$ ) does not alter the gap between the stationary amounts $\bar{b}^{1}$ and $\bar{b}^{2}$ of bequest. However, the effect of a pay-as-you-go social security system on income distribution and on intergenerational mobility in human capital depend on whether the economy is dynamically efficient or inefficient as defined by Cass (1979). In particular, an increase in $\lambda$ has the following effects:

$$
\frac{\partial \Pi}{\partial \lambda}=\left(\frac{\Pi}{\left(1-\tau_{w}\right) w-\Omega}\right)\left(1-\frac{n}{R\left(\tau_{k}\right)}\right),
$$

and

$$
\frac{\partial \widetilde{b}^{0}}{\partial \lambda}=\frac{1}{1-\tau_{b}}\left(1-\frac{n}{R\left(\tau_{k}\right)}\right) .
$$

If $R\left(\tau_{k}\right)>n$, the social security program raises the relative difference $\Pi$ of income but reduces the fraction of educated individuals. In this case, income inequality increases if the second effect is small, which occurs when the distribution function is inelastic or the fraction of educated individuals is sufficiently small. The opposite effects occur when $R\left(\tau_{k}\right)<n$. In this case, income inequality increases when the distribution function is either sufficiently elastic or the fraction of educated individuals is sufficiently large. 
The social security program distorts the decisions on bequest and education investment by affecting the marginal utility loss derived from reducing consumption in order to increase the amount of bequest left to children. In particular, there may exist a wedge between the returns on saving given by $R\left(\tau_{k}\right)$ and the returns of social security program given by $n$. Thus, this policy can alter the present value to the lifetime income that individuals devote to own consumption given the amount of bequest that they will leave to their children. If $R\left(\tau_{k}\right)>n$, then the social security program reduces the present value of lifetime income of individuals. Therefore, in this case this policy reduces the willingness of parents to leave bequest and to invest in the education of their children. Evidently, the opposite conclusion arises when $R\left(\tau_{k}\right)<n$.

\section{Labor income taxes vs. inheritance taxes}

We have seen in the previous section that both inheritance and labor income taxes reduce aggregate income and they may also reduce income inequality. In this section we discuss which of these two taxes is the best tax instrument in terms of aggregate income and income inequality. We address this question by comparing the effects on aggregate income and income inequality of substituting labor income taxes by inheritance taxes. We consider two different fiscal policy scenarios: first, taxes are used to finance government spending and, second, they are used to finance an education subsidy. Since we want to characterize the effects of fiscal policy on the long-run equilibrium, we constrain the parameter values of the model in order to guarantee convergence to the two-point distribution considered in Section 4.2.

Regarding fiscal policy, for the sake of simplicity, we assume that $\tau_{k}=\lambda=\theta=0$. Taking into account that the equilibrium converges to a two-point distribution, the government budget constraint (7) in the long run simplifies to

$$
G+n^{2} \mu(1-\alpha) s_{e}=n w[1+(1-\alpha) \varepsilon] \tau_{w}+n \bar{b} \tau_{b},
$$

where $\bar{b}=\alpha \bar{b}^{1}+(1-\alpha) \bar{b}^{2}$. We also assume that initially there is no government spending nor education subsides and that the tax rate on inheritance and labor income are initially set equal to zero, $G=s_{e}=\tau_{w}=\tau_{b}=0$. Then, we will characterize the effects of introducing fiscal policy instruments. In order to do so, we totally differentiate the previous government budget constraint evaluated at $G=s_{e}=\tau_{w}=\tau_{b}=0$ to obtain

$$
d G+n^{2}(1-\alpha) \mu d s_{e}=n w[1+(1-\alpha) \varepsilon] d \tau_{w}+n \bar{b} d \tau_{b} .
$$

This equation shows the relationship between the increases in taxes, government spending, and subsidies that balance the government budget when fiscal policy is introduced. As follows from equation (36), this relationship depends on the value of $\alpha$. Therefore, the increase in the tax rates needed to accommodate the introduction of either government spending or education subsidies depends on the long-run fraction of educated individuals. In the fiscal policy experiments that we will perform in this section, taxes are set endogenously to balance the government budget constraint, whereas in the fiscal policy experiments in Section 5 government spending endogenously adjusted to tax shocks. Finally, because of the endogeneity of taxes, the effects of fiscal policy on aggregate variables depend on the initial joint distribution of bequest and education among individuals. 
The aim of this section is to study the effects of fiscal policies on both aggregate income and income inequality. The effects on aggregate income are obtained by totally differentiating (28) and making $G=s_{e}=\tau_{w}=\tau_{b}=0$,

$$
\widetilde{d b}^{0}=\widetilde{b}^{0} d \tau_{b}-\frac{n(1+\rho+\beta) \mu}{\beta} d s_{e}+w d \tau_{w} .
$$

Similarly, the effects on income inequality are obtained by totally differentiating $M$ and making $G=s_{e}=\tau_{w}=\tau_{b}=0$

$$
d M=-\frac{\alpha \psi \Pi}{\widetilde{b}_{0}} d \widetilde{b}_{0}+(1-\alpha) d \Pi,
$$

where $\widetilde{d b}_{0}$ is defined in $(37)$ and

$$
d \Pi=\left(\frac{\beta}{1+\rho+\beta}\right)\left(\frac{R \mu}{w}\right)\left(d \tau_{b}+d s_{e}-d \tau_{w}\right) .
$$

We will next study the implications of using labor income taxes instead of inheritance taxes to finance the introduction of either government spending or education subsidies.

\subsection{Introducing government spending}

As in the previous section, the introduction of government spending reduces the number of educated individuals when it is financed by either inheritance taxes or labor income taxes. Increasing any of these two taxes reduces the disposable income of parents and therefore reduces the number of educated families in the long run. This results in a reduction of both the stock of human capital and aggregate income. The following proposition shows that this reduction is larger when government spending is financed by means of inheritance taxes:

Proposition 2 The marginal introduction of government spending financed with either inheritance taxes or labor income taxes decreases aggregate income. This reduction of aggregate income is smaller if the same marginal introduction of government spending is financed with labor income taxes.

The marginal effects of fiscal policy on education depend on how these policies affect the income of the marginal individual who is not educated but educates their descendants. Note that this individual will have a sufficiently large amount of bequest to educate their children, but a low salary. As a consequence, when government spending is financed with a tax on inheritances this individual will suffer a larger reduction in income than when government spending is financed with a tax on labor income. Therefore, the last part of the previous proposition follows as inheritance taxes imply a larger increase in the threshold value $\widetilde{b}_{0}$ of bequest.

The introduction of government spending also changes income inequality as the following proposition shows:

Proposition 3 Let us define

$$
\widetilde{\alpha}=\frac{1}{\psi\left(\frac{\varepsilon w}{R \mu}-1\right)+1} \in(0,1)
$$


and

$$
\bar{\alpha}=\frac{1}{\varphi(\bar{\alpha}) \psi\left(\frac{\varepsilon w}{R \mu}-1\right)+1} \in(0,1),
$$

where $\bar{\alpha}>\widetilde{\alpha}$. Then,

(a) The marginal introduction of government spending financed with labor income taxes reduces income inequality. Moreover, if $\alpha>(<) \widetilde{\alpha}$ then the marginal introduction of government spending financed with inheritance taxes reduces (increases) income inequality.

(b) Assume that $\alpha>\widetilde{\alpha}$. If $\alpha<(>) \bar{\alpha}$, then the reduction of income inequality is larger when the same marginal introduction of government spending is financed with labor income taxes (inheritance taxes).

According to the previous proposition, the introduction of government spending financed with taxes may reduce income inequality. On the one hand, due to the skill premium, taxes on labor income reduce more the income of educated individuals than of non-educated. On the other hand, the effect of inheritance taxes on income inequality is ambiguous and depends on the long-run frequency of educated individuals. Whether or not the reduction in income inequality is larger when government spending is financed with taxes on labor income or on inheritances will depend on the long-run frequencies of the two groups. These frequencies determine the corresponding tax bases and, thus, the increase in the tax rates necessary to finance the marginal introduction of government spending. It can be proved that the base of the inheritance tax is smaller than the base of the tax on labor income when the fraction $\alpha$ of non-educated is sufficiently small. In this case, the marginal introduction of government spending requires a larger increase in $\tau_{b}$ than in $\tau_{w}$.

We summarize the results of this section by saying that, for those economies displaying a low level of government spending and a sufficiently large value of $\alpha(\alpha>\bar{\alpha})$, the substitution of taxes on labor income for inheritance taxes reduces income inequality and increases aggregate income by raising the number of educated individuals in the long run. However, if $\alpha<\bar{\alpha}$ then substituting inheritance taxes for labor income taxes implies the classical trade-off between income inequality and aggregate income.

\subsection{Introducing education subsidies}

In the previous section we have shown that the introduction of subsidies to education implies larger income inequality and larger aggregate income. The opposite effects may arise when taxes on inheritances or on labor income are introduced. Therefore, the effects of the introduction of a subsidy financed with these taxes are not obvious at first glance. We first characterize the effects on aggregate income of the introduction of an education subsidy.

Proposition 4 The introduction of an education subsidy financed with either labor income taxes or inheritance taxes increases aggregate income. This increase is larger if the same marginal introduction of the subsidy is financed with labor income taxes.

The education subsidy reduces the cost of education and, therefore, increases the number of educated families. Moreover, using labor income taxes instead of inheritance taxes to finance the education subsidy increases aggregate income. As we showed when 
discussing the introduction of government spending, the intuition for the previous result is based on the differential effects of these taxes on the income of the marginal noneducated individual who decides to educate their descendants.

We next present the effects on income inequality between educated and noneducated individuals of increasing the subsidy to education

Proposition 5 (a) The marginal introduction of an education subsidy financed with either labor income taxes or inheritance taxes increases income inequality.

(b) If $\alpha>(<) \bar{\alpha}$, then the increase in income inequality is larger when the same marginal introduction of an education subsidy is financed with labor income taxes (inheritance taxes).

Part (a) of the previous proposition tells us that the marginal introduction of a subsidy to education increases income inequality. This is a consequence of the fact that these subsidies only benefit educated individuals. Part (b) follows from the same argument as in Proposition 3, namely, that the fraction $\alpha$ of non-educated individuals fully determines the corresponding tax bases and thus the required increase in the tax rates to finance the marginal introduction of the education subsidy.

The introduction of subsidies to education financed with either labor income taxes or inheritance taxes implies the typical trade-off between inequality and income. The substitution of the inheritances tax by the labor income tax implies this trade-off only when the fraction of non-educated individuals is sufficiently large. In contrast, in societies with a large fraction of educated individuals, this substitution increases income and reduces income inequality. We have thus shown that the effects of fiscal policy on important economic variables may depend on the initial distribution of individuals between the two groups.

\section{Conclusion}

In this paper we have analyzed how the initial distribution and composition of wealth between bequest and human capital characterize the evolution of both the distribution of income and the intergenerational mobility in human capital. There are three main assumptions that give rise to our results. First, the education of individuals can only be financed by their parents, who derive satisfaction from their contribution to the lifetime income of their children with independence of the type of the intergenerational transfers used for that purpose. Second, we assume that the acquisition of human capital is indivisible and requires thus a minimum amount of investment. Finally, parents cannot force children to give them transfers, so that those parents with a sufficiently small income will not invest in the education of their children. Hence, intragenerational income distribution and intergenerational mobility in human capital are affected by the percentage of individuals who inherited a sufficiently large amount of physical wealth to enable them to invest in the education of their offspring. Furthermore, the minimum amount of inheritance required by educated parents to give education to their children differs from the minimum amount for non-educated parents.

From our results we can conclude that the cross-country differences in the composition of intergenerational transfers, income inequality, and mobility are driven by (i) the initial distribution of both wealth and human capital; (ii) the correlation 
between these two initial distributions; (iii) differences in the process of human capital accumulation; and (iv) differences in the fiscal policy set by the governments.

We have shown how different fiscal instruments affect both aggregate income and income inequality through two different policy exercises. In Section 5, we have analyzed the effects of a fiscal policy instrument when government spending accommodates any fiscal shock to satisfy the government budget constraint. We show that increasing the tax rate on inheritances or on labor income reduces human capital accumulation, raising the rate of the education subsidy increases human capital accumulation, and social security increases human capital accumulation if and only if the economy is dynamically inefficient. Regarding the effects on income inequality, an increase in labor income taxes reduces inequality, whereas an increase in capital income taxes or education subsidies increase inequality. The effects of inheritances taxes and social security on income inequality depend on the initial fraction of educated individuals.

In Section 6 we have analyzed the effects of using labor income taxes instead of inheritance taxes to finance either government spending or education subsidies. This substitution increases human capital accumulation and, hence, aggregate income increases. In contrast, the effects of this substitution on income inequality depend on the initial fraction of non-educated individuals. In societies with an initially low fraction of non-educated individuals using labor income taxes instead of inheritances taxes increases income and reduces inequality. In contrast, in societies with an initially large fraction on non-educated individuals the substitution between these two taxes necessary implies the traditional trade-off between aggregate income and income inequality.

As we have mentioned in the introduction a natural extension of our analysis would be the introduction of idiosyncratic, stochastic individual abilities so as to obtain random mobility between two consecutive generations. However, in this generalized setup the composition of initial transfers will play a similar role as in our deterministic model. 


\section{References}

[1] Acemoglu, D., 2002. Technical change, inequality, and the labor market. Journal of Economic Literature 40, 7-72.

[2] Aghion, P., Caroli, E., García-Peñalosa, C., 1999. Inequality and economic growth: the perspective of the new growth theories. Journal of Economic Literature 38, $1615-1660$.

[3] Autor, D.H., Katz, L.F., Krueger, A.B., 1998. Computing inequality: have computers changed the labor market. Quarterly Journal of Economics 113, 11691213.

[4] Barro, R., Lee, J.W., 2001. International data on educational attainment updates and implications. Oxford Economic Papers 53, 541-563.

[5] Becker, G.S., Tomes, N., 1976. Child endowments and the quantity and quality of children. Journal of Political Economy 84, S14-S162.

[6] Becker, G.S., Tomes, N., 1986. Human capital and the rise and fall of families. Journal of Labor Economics 4, S1-S38.

[7] Behrman, J., Pollak, R., and Taubman. P., 1995. The wealth model: efficiency in education and distribution in the family. In: Behrman, J., Pollak, R., and Taubman. P. (Eds.). From Parent to Child: Intra-household Allocations and Intergenerational Relations in the United States. Chicago: University of Chicago Press, 138-182.

[8] Bound, J., Johnson, G., 1992. Changes in the structure of wages in the 1980's: An evaluation of alternative explanations. American Economic Review 82, 371-392.

[9] Cass, D., 1972. On capital overaccumulation in the aggregate, neoclassical model of economic growth: a complete characterization. Journal of Economic Theory 4, 200-223.

[10] Checchi, D., García-Peñalosa, C., 2004. Risk and the distribution of human capital. Economic Letters 82, 53-61.

[11] d'Addio, A.C., 2007. Intergenerational transmission of disadvantage: mobility or immobility across generations? A Review of the Evidence for OECD Countries. OECD Social, Employment and Migration Working Papers 52.

[12] Dynarski, S., 2002. The behavioural and distributional implications of aid for college. American Economic Review (Papers and Proceedings) 92 , 279-285.

[13] Eckstein, Z., Zilcha, I., 1994. The effects of compulsory schooling on growth, income distribution and welfare. Journal of Public Economics 54, 339-359.

[14] Galor, O., Moav, O., 2004. From physical to human capital accumulation: inequality and the process of development. Review of Economic Studies 71, 10011026.

[15] Galor, O., Moav, O., 2006. Das human-kapital: a theory of the demise of the class-structure. Review of Economic Studies 73, 85-117. 
[16] Galor, O., Tsiddon, D., 1997. The distribution of human capital, technological progress, and economic growth. Journal of Economic Growth 2, 93-124.

[17] Galor, O., Zeira, J., 1993. Income distribution and macroeconomics. Review of Economic Studies 60, 35-52.

[18] García-Peñalosa, C., 1994. Inequality and growth: a note on recent theories. Investigaciones Económicas 18, 97-116.

[19] García-Peñalosa, C., 1995. The paradox of education or the good side of inequality. Oxford Economic Papers 47, 265-285.

[20] Gokhale, J. Kotlikoff, L.J., 2002. Simulating the transmission of wealth inequality. American Economic Review (Papers and Proceedings) 92, 265-269.

[21] Gokhale, J., Kotlikoff, L.J., Segton, J., Weale, M., 2001. Simulating the transmission of wealth inequality via bequests. Journal of Public Economics 79, 93-128.

[22] Keane, M.P., 2002. Financial aid, borrowing constraints, and college attendance: Evidence from structural estimates. American Economic Review (Papers and Proceedings) 92, 293-297.

[23] Laitner, J., 2002. Wealth inequality and altruistic bequest. American Economic Review (Papers and Proceedings) 92, 270-273.

[24] Michel, P., Thibault, E., Vidal, J.P., 2006. Intergenerational altruism and neoclassical growth models. In: Kolm, S.C., Ythier J.M. (Eds.). Handbook of the Economics of Giving, Reciprocity and Altruism, Amsterdam: Noth-Holland, $1055-1106$.

[25] Nordblom, K., Ohlsson, H., 2011. Bequests, gifts, and education: links between intergenerational transfers. Empirical Economics 40, 343-358.

[26] Owen, A.L., Weil, D.N., 1998. Intergenerational earnings mobility, inequality and growth. Journal of Monetary Economics 41, 71-104.

[27] Zilcha, I., 2003. Intergenerational transfers, production and income distribution. Journal of Public Economics 87, 489-513.

[28] Wolf, E.N., 2002. Inheritances and wealth inequality, 1989-1998. American Economic Review (Papers and Proceedings) 92, 260-264. 


\section{Appendix}

\section{A Optimality conditions of the individual problem}

We derive in this appendix the optimal conditions on $c_{t}^{i}, x_{t}^{i}, s_{t}^{i}$ and $b_{t+1}^{i}$. To this end we take the value of $e_{t}^{i}$ as given. First, by combining (4) and (5) we obtain the following intertemporal budget constraint:

$$
\left(1-\tau_{w}\right) w_{t} h_{t}^{i}+\left(1-\tau_{b}\right) b_{t}^{i}-\Omega=c_{t}^{i}+\left(1-s_{e}\right) n e_{t}^{i}+\frac{x_{t+1}^{i}+n b_{t+1}^{i}}{R\left(\tau_{k}\right)} .
$$

Second, consider the problem consisting on maximizing (1) with respect to $\left\{c_{t}^{i}, x_{t+1}^{i}, b_{t+1}^{i}\right\}$ subject to (A.1) and (6). Denote by $\psi$ the Lagrangian multiplier associated with the constraint (A.1). The first order conditions of the previous problem are given by

$$
\begin{gathered}
c_{t}^{i}=\frac{1}{\psi}, \\
x_{t+1}^{i}=\frac{\rho R\left(\tau_{k}\right)}{\psi},
\end{gathered}
$$

and

$$
\frac{\beta\left(1-\tau_{b}\right)}{I_{t+1}^{i}} \leq \frac{n \psi}{R\left(\tau_{k}\right)}
$$

By combining (A.2) and (A.3), we directly get (8). Moreover, from (A.2) and (A.3) we obtain

$$
c_{t}^{i}+\frac{x_{t+1}^{i}}{R\left(\tau_{k}\right)}=\frac{1+\rho}{\psi} .
$$

Combining (A.1), (A.4), and (A.5) we can easily derive condition (9). Finally, after solving for $\psi$ in condition (A.4) when it holds with equality and substituting the result in (A.2) and (A.3), we obtain conditions (12) and (13).

\section{B Different configurations of the stationary distribution}

Under the maintained condition (23), the conditions (25) and (29) determine the configuration of the stationary distribution of physical bequest and human capital. In particular, the following configurations of the stationary distribution can emerge in our economy:

1. When condition (25) does not hold, then no stable stationary distribution exists.

2. When condition (25) holds, the economy converges to a degenerate distribution if condition (29) is not satisfied. In this case, the fixed point $\bar{b}^{2}$ is the unique interior steady-state. In this steady-state all the dynasties invest in their children's education and leave an amount of bequest equal to $\bar{b}^{2}$.

3. Finally, when the conditions (25) and (29) hold, then the economy converges to a two-point distribution where some dynasties leave a bequest per children equal to $\bar{b}^{1}$ and do not invest in their education, whereas the rest of dynasties do invest in the education of their children and leave a bequest per capita equal to $\bar{b}^{2}$. 


\section{Proofs of the Propositions of Section 6}

Proof of Proposition 2. We assume that $d s_{e}=0$ and we use (36) and (37) to obtain

$$
\left.\frac{\widetilde{d b^{0}}}{d G}\right|_{d \tau_{w}=0}=\frac{\widetilde{b}^{0}}{n \bar{b}}>0
$$

and

$$
\left.\frac{\widetilde{d b^{0}}}{d G}\right|_{d \tau_{b}=0}=\frac{1}{n[1+(1-\alpha) \varepsilon]}>0 .
$$

The increase in $\widetilde{b}^{0}$ is larger when government spending is financed with inheritance taxes if the following inequality holds:

$$
\left.\frac{\widetilde{d b^{0}}}{d G}\right|_{d \tau_{w}=0}>\left.\frac{\widetilde{d b^{0}}}{d G}\right|_{d \tau_{b}=0} .
$$

This inequality simplifies to

$$
\widetilde{b}^{0}[1+(1-\alpha) \varepsilon]>\bar{b}
$$

To prove that (40) holds, we need the following lemma:

Lemma 6 The following inequalities hold:
(a) $\varepsilon>\frac{\bar{b}^{2}-\bar{b}^{1}}{\bar{b}^{1}}$
(b) $\varepsilon>\frac{\bar{b}^{2}-\bar{b}^{1}}{\widetilde{b}^{0}}$, and
(c) $\varepsilon>\frac{\bar{b}^{2}-\widetilde{b}^{0}}{\widetilde{b}^{0}}$.

Proof. Using (21) and (22), it can be shown that (a) is equivalent to

$$
0>-n \mu-\frac{n(1+\rho) w \varepsilon}{\beta R},
$$

which is obviously satisfied. Moreover, (a) and $\widetilde{b}^{0}>\bar{b}^{1}$ imply (b) and (c).

Condition (40) holds if $Q(\alpha)>0$, where

$$
Q(\alpha)=\widetilde{b}^{0}(1+\varepsilon)-\bar{b}^{2}-\alpha\left(\varepsilon \widetilde{b}^{0}+\bar{b}^{1}-\bar{b}^{2}\right) .
$$

Note that $Q(1)=\widetilde{b}^{0}-\bar{b}^{1}>0$, and the inequalities in the Lemma 6 imply that

$$
Q(0)=\widetilde{b}^{0}(1+\varepsilon)-\bar{b}^{2}>0
$$

and

$$
Q^{\prime}(\alpha)=-\left(\varepsilon \widetilde{b}^{0}+\bar{b}^{1}-\bar{b}^{2}\right)<0 .
$$

This implies that $Q(\alpha)>0$ for all values of $\alpha$, which means that condition (40) holds. 
Proof of Proposition 3. (a) We combine (36), (37), (38), and (39) to obtain

$\left.\frac{d M}{d G}\right|_{d \tau_{b}=0}=-\left(\frac{\beta}{1+\rho+\beta}\right)\left(\frac{1}{n[1+(1-\alpha) \varepsilon]}\right)\left[(1-\alpha)\left(\frac{R \mu}{w^{2}}\right)+\frac{\alpha \psi}{\widetilde{b}_{0}}\left(\varepsilon-\frac{R \mu}{w}\right)\right]<0$

and

$$
\left.\frac{d M}{d G}\right|_{d \tau_{w}=0}=\left(\frac{\beta}{1+\rho+\beta}\right)\left(\frac{1}{n \bar{b}}\right)\left[(1-\alpha)\left(\frac{R \mu}{w}\right)-\alpha \psi\left(\varepsilon-\frac{R \mu}{w}\right)\right] .
$$

It is immediate to see that there exists a value of $\alpha, \widetilde{\alpha}$, such $\left.\frac{d M}{d G}\right|_{d \tau_{w}=0} \geq(<) 0$ if $\alpha \leq(>) \widetilde{\alpha}$, where $\widetilde{\alpha}$ is defined in the statement of the proposition and (14) implies that $\widetilde{\alpha} \in(0,1)$.

(b) Note that

when $\alpha=0$, whereas

$$
\left.\frac{d M}{d G}\right|_{d \tau_{b}=0}<\left.\frac{d M}{d G}\right|_{d \tau_{w}=0}
$$

$$
\left.\frac{d M}{d G}\right|_{d \tau_{b}=0}<\left.\frac{d M}{d G}\right|_{d \tau_{w}=0}
$$

when $\alpha=1$. Moreover, given the expressions for the two derivatives, there exists a unique value $\bar{\alpha} \in(0,1)$ such that

$$
\left.\frac{d M}{d G}\right|_{d \tau_{b}=0}=\left.\frac{d M}{d G}\right|_{d \tau_{w}=0} .
$$

Therefore,

$$
\left.\frac{d M}{d G}\right|_{d \tau_{b}=0}>\left.\frac{d M}{d G}\right|_{d \tau_{w}=0}
$$

if and only if $\alpha>\bar{\alpha}$, where

$$
\bar{\alpha}=\frac{1}{\varphi(\bar{\alpha}) \psi\left(\frac{\varepsilon w}{R \mu}-1\right)+1}
$$

and

$$
\varphi(\alpha)=\frac{1-\frac{\bar{b}}{[1+(1-\alpha) \varepsilon] \widetilde{b}_{0}}}{1+\frac{\bar{b}}{w[1+(1-\alpha) \varepsilon]}} .
$$

Note that (40) implies that $\varphi(\alpha) \in(0,1)$ and (14) implies that $\bar{\alpha} \in(0,1)$. It is straightforward to show that $\bar{\alpha}>\widetilde{\alpha}$ as $\varphi(\alpha) \in(0,1)$

Proof of Proposition 4. We use (36) and (37) to obtain the effects of the introduction of a subsidy when it is financed with labor income taxes,

$$
\left.\frac{\widetilde{d b^{0}}}{d s_{e}}\right|_{d \tau_{b}=0}=n \mu\left[\frac{(1-\alpha)}{1+(1-\alpha) \varepsilon}-\frac{(1+\rho+\beta)}{\beta}\right]<0,
$$

and when it is financed with inheritance taxes,

$$
\left.\frac{d \widetilde{b}^{0}}{d s_{e}}\right|_{d \tau_{w}=0}=n \mu\left[\frac{(1-\alpha) \widetilde{b}^{0}}{\bar{b}}-\frac{1+\rho+\beta}{\beta}\right]<0,
$$


since $(1-\alpha) \widetilde{b}^{0}<(1-\alpha) \bar{b}^{2}<\bar{b}$. These inequalities imply that the introduction of an education subsidy increases social mobility, which in turn increases aggregate income in the long run.

Moreover, the inequality

$$
\left.\frac{d \widetilde{b}^{0}}{d s_{e}}\right|_{d \tau_{w}=0}>\left.\frac{\widetilde{d b^{0}}}{d s_{e}}\right|_{d \tau_{b}=0}
$$

holds when $[1+(1-\alpha) \varepsilon] \widetilde{b}^{0}>\bar{b}$. In the proof of Proposition 2 we have already shown that this inequality is satisfied.

Proof of Proposition 5. (a) We use (38), (37), (39) and (36) to obtain

$$
\left.\frac{d M}{d s_{e}}\right|_{d \tau_{w}=0}=\left(\frac{\beta}{1+\rho+\beta}\right)\left[\begin{array}{c}
\alpha \psi n \mu\left(\varepsilon-\frac{R \mu}{w}\right)\left(\frac{(1+\rho+\beta)}{\widetilde{b}_{0} \beta}-\frac{(1-\alpha)}{\bar{b}}\right) \\
+(1-\alpha)\left(\frac{R \mu}{w}\right)\left(\frac{n(1-\alpha) \mu}{\bar{b}}+1\right)
\end{array}\right]>0
$$

and

$$
\left.\frac{d M}{d s_{e}}\right|_{d \tau_{b}=0}=\left(\frac{\beta}{1+\rho+\beta}\right)\left[\begin{array}{c}
-\frac{\alpha \psi n \mu}{\widetilde{b}_{0}}\left(\varepsilon-\frac{R \mu}{w}\right)\left(\frac{(1-\alpha)}{1+(1-\alpha) \varepsilon}-\frac{(1+\rho+\beta)}{\beta}\right) \\
+(1-\alpha)\left(\frac{R \mu}{w}\right)\left(1-\frac{n(1-\alpha) \mu}{w[1+(1-\alpha) \varepsilon]}\right)
\end{array}\right]>0
$$

where the positive signs follow from (14), $\bar{b}^{2}>\widetilde{b}_{0}$, and (23).

(b) Following the same steps as in the proof of part (b) of Proposition 3, it is immediate to see that

holds if and only $\alpha>\bar{\alpha}$.

$$
\left.\frac{d M}{d s_{e}}\right|_{d \tau_{b}=0}>\left.\frac{d M}{d s_{e}}\right|_{d \tau_{w}=0}
$$




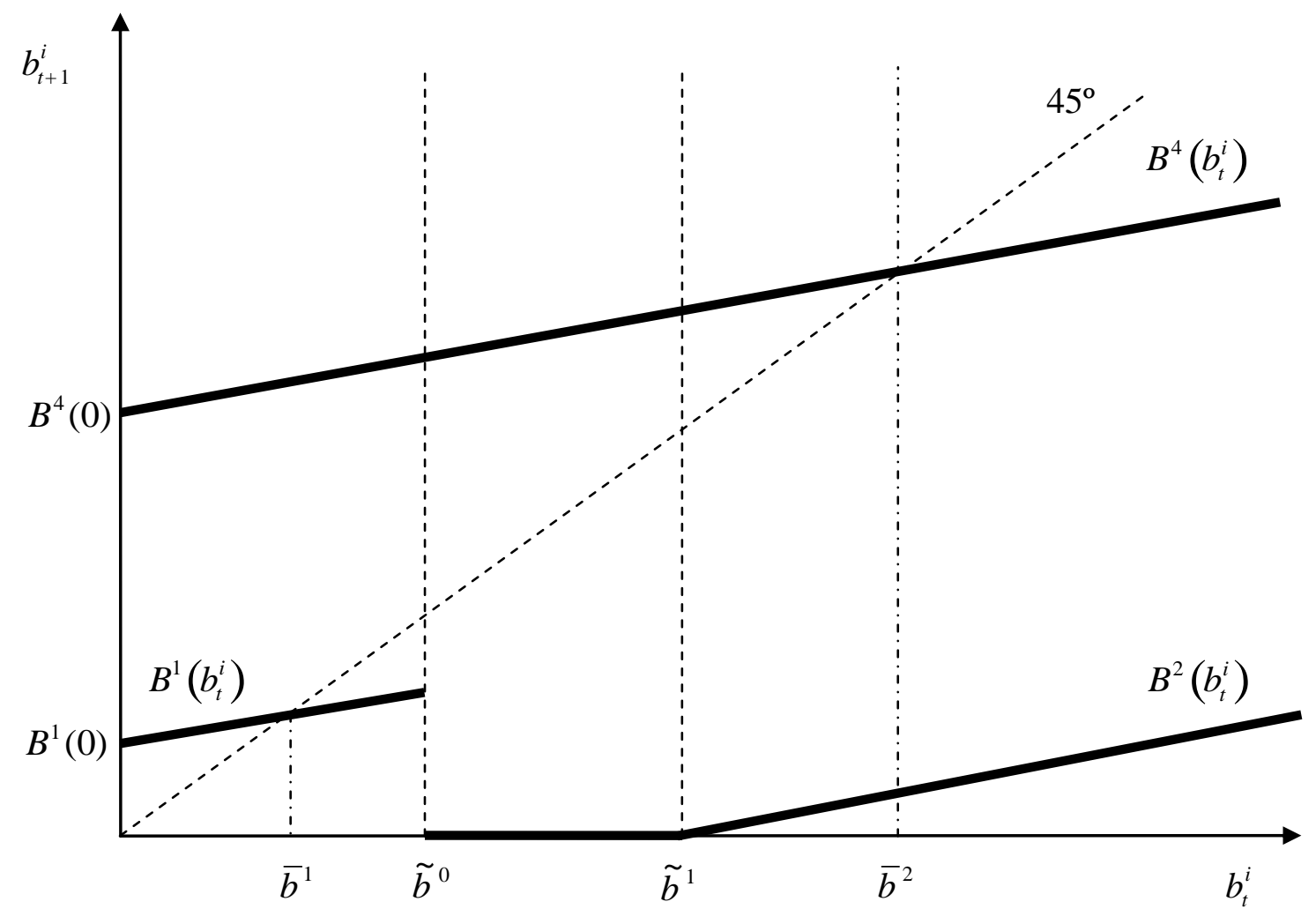

Figure 1. The dynamics of bequests. 


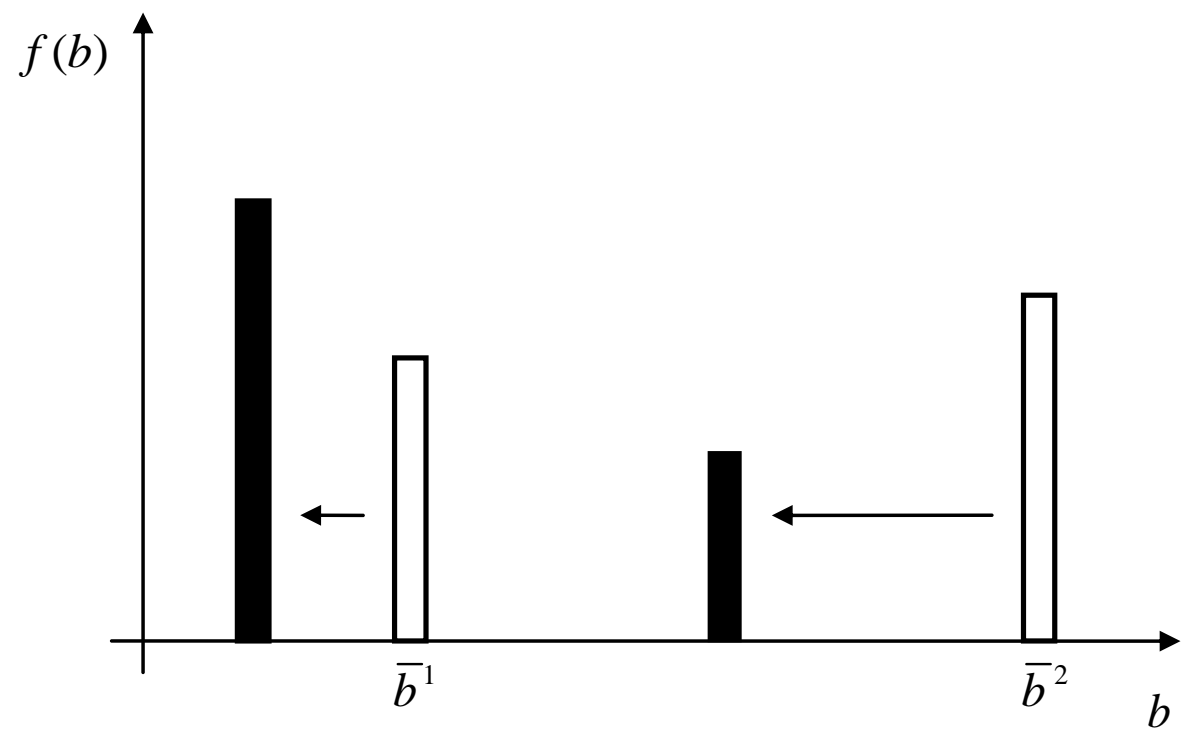

Figure 2. The effect on the distribution of bequests of a rise in the inheritance tax or in the labor income tax. 


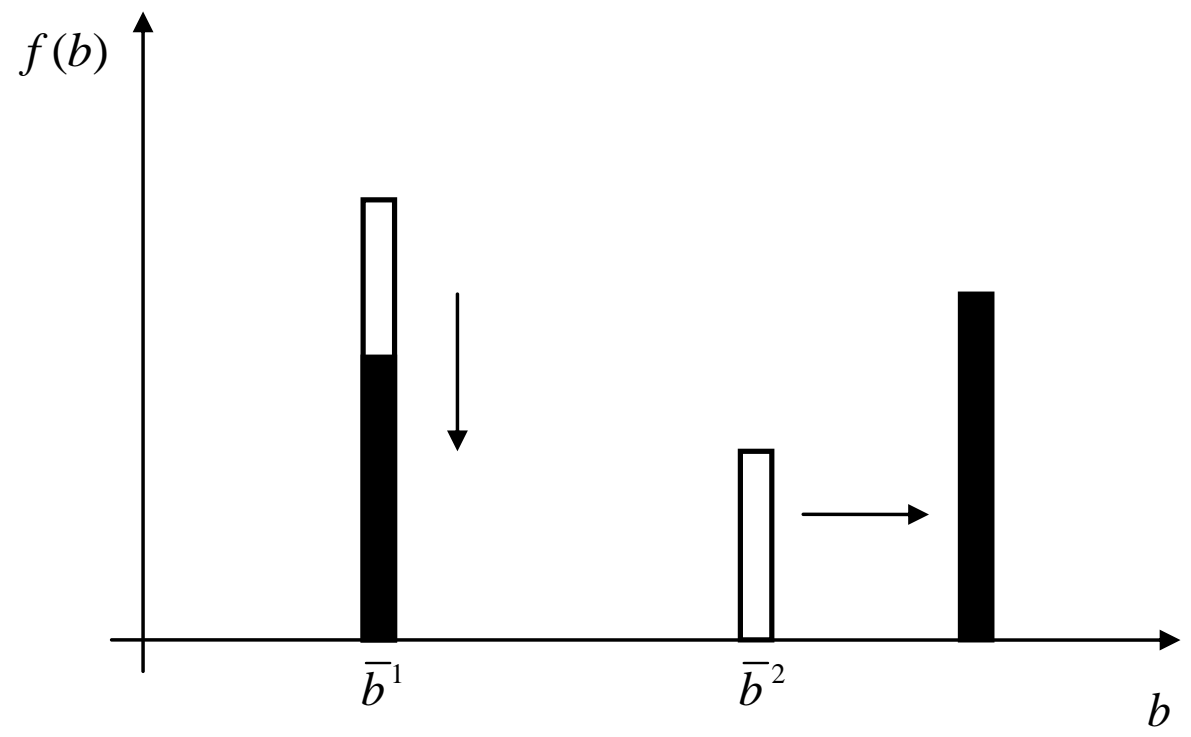

Figure 3. The effect of a rise in the education subsidy rate. 